\title{
Lazos entre arqueología, arquitectura y restauración: cuatro casos y una reflexión
}

\author{
Links between archaeology, architecture and restoration: \\ four cases and one thought
}

\author{
${\text { Camilla } \text { Mileto }^{1} \text {, Fernando Vegas }}^{2}$ \\ Universitat Politècnica de València
}

\section{RESUMEN}

La relación entre arqueología de la arquitectura y restauración del patrimonio arquitectónico está reconocida desde hace tiempo. Tras una introducción inicial a la cuestión, este artículo presenta cuatro casos concretos de estudios, proyectos y obras de restauración y rehabilitación donde se refleja esta relación entre las dos disciplinas con variantes derivadas de las diferencias del patrimonio construido en cuestión como de metodología de estudio y planteamiento de intervención. El recorrido propuesto describe un abanico variado de las posibilidades de aplicación y respuesta a una intervención arquitectónica con mentalidad estratigráfica. Los casos presentados permiten extraer una reflexión sobre el crecimiento común de las dos disciplinas en los treinta años de andadura, donde cada una ha aportado a la otra una forma de mirar e interpretar, además de los avances científicos concretos que han venido a completar y enriquecer la visión.

Palabras clave: arquitectura; restauración; conservación; rehabilitación.

\section{ABSTRACT}

The relationship between architectural archaeology and restoration of architectural heritage has long been known. Following an initial introduction, this paper presents four specific case studies on designs and work in restoration and rehabilitation, which reflect the relationship between these two $d$ isciplines, a s w ell a s variants resulting from differences in built heritage in terms of study methodology and intervention proposals. The proposed plan describes a wide range of possibilities for application and response to an architectural intervention focusing on stratigraphy. The case studies support an analysis of the shared growth of both disciplines over the past thirty years, and of the specific scientific advances which have completed and enriched this vision just as their views and interpretations have complemented each other.

Key words: architecture; restoration; conservation; rehabilitation.

Recibido: 16-05-2018. Aceptado: 19-09-2018. Publicado online: 23-09-2019

\section{Cómo citar este artículo / Citation}

Mileto, C. y Vegas, F. 2019: "Lazos entre arqueología, arquitectura y restauración: cuatro casos y una reflexión", Arqueología de la Arquitectura, 16: e087. https://doi.org/10.3989/arq.arqt.2019.009

Copyright: (c) CSIC, 2019. (c) UPV/EHU Press, 2019. Este es un artículo de acceso abierto distribuido bajo los términos de la licencia de uso y distribución Creative Commons Reconocimiento 4.0 Internacional (CC BY 4.0).

\footnotetext{
cami2@cpa.upv.es / ORCID iD: https://orcid.org/0000-0002-6987-8802

2 fvegas@cpa.upv.es / ORCID iD: https://orcid.org/0000-0003-0315-6839
} 


\section{ARQUEOLOGÍA Y RESTAURACIÓN DE LA ARQUITECTURA}

La arqueología constituye una disciplina que, por su propia naturaleza de investigación histórica de la cultura material, tiene una amplia aplicación al estudio y la conservación del patrimonio histórico arquitectónico ya sea arquitectura monumental, arquitectura vernácula, paisaje cultural, conjuntos urbanos y rurales, etc. $\mathrm{Su}$ aplicación como seguimiento arqueológico y excavación arqueológica se ha ido fortaleciendo en el tiempo hasta incluirse de pleno derecho en los procesos de documentación relacionada con la intervención. Las normas y leyes obligan a emplear estos métodos sobre todo en la fase de seguimiento de una obra que pueda afectar al subsuelo. Sin embargo, la arqueología, o la arqueo-lógica (Criado Boado 2012), puede contribuir de una forma mucho más amplia y profunda si se entiende cuáles son los puntos de conexión con el propio proceso de estudio, proyecto y realización de la obra de restauración de la arquitectura.

La forma de plantear un proyecto de restauración está ligada a la concepción de arquitectura histórica, tanto como al reconocimiento de los valores y a las aspiraciones culturales. No existe una forma unívoca de plantear un proyecto y por ello, a menudo, parece que el resultado de las intervenciones dependa de la sensibilidad de los proyectistas (Blanco 2017). Se puede llamar sensibilidad, formación, visión, aspiración cultural... El hecho es que, frente a un mismo edificio, se puede actuar de forma muy diferente a tenor del planteamiento cultural de cada quien. No existe una regla fija porque el proyecto de restauración se genera en un entorno cultural que varía en el tiempo sujeto a diversas sinergias. Esto, sin embargo, no significa en absoluto que deba permitirse la improvisación y la ligereza en la toma de decisiones.

Las cartas de restauración aprobadas por ICOMOS, los documentos internacionales (AA. VV. 2003b) y las leyes de patrimonio (Martínez Justicia y SánchezMesa 2008) han ido definiendo progresivamente los límites, objetivos y modalidades de las intervenciones de restauración arquitectónica (Mileto y Vegas 2017). En estos documentos ${ }^{3}$, el objeto de la restauración ha ido

\footnotetext{
Se recogen aquí, de una forma esquemática, los términos y conceptos empleados en los siguientes documentos: Voto del III Congresso degli Ingegneri e architetti italiani (1883), Carta de Aten as (1931), Carta del Restauro (1932), Convenio de La Haya (1954), Carta De Venecia (1964), Normas de Quito (1967), Carta Italiana del Restauro (1972), Carta Europea del Patrimonio
}

ampliándose desde el concepto de monumento (1883), hasta el ambiente del monumento (1931), el monumento aislado o de conjunto y rural o urbano (1964), los centros históricos (1972), el patrimonio arquitectónico (1975), los centros urbanos (1987), el patrimonio cultural (1994), el patrimonio vernáculo (1999), el patrimonio cultural inmaterial (2003), etc. Así, se han ido ampliando los valores que se identifican en el patrimonio: desde el valor artístico, documental ya definidos en 1883, hasta una amplia lista que comprende el valor histórico, el valor de antigüedad y el valor social afectivo (1931), el valor de identidad (1932), el valor como testimonio de un patrimonio común y el valor de autenticidad (1964), el valor económico, ambiental, cultural (1967), el valor espiritual, social y educativo (1975), el valor científico (1994), el valor cultural local y territorial, el valor de utilidad, el valor como documento de los cambios (1999), el valor de creatividad, de continuidad (2003), el valor de capacitación profesional (2005), el valor lúdico (2010), etc.

Por todo ello, ya en 1883 se definieron los criterios y principios generales a aplicar en las actuaciones que se tradujeron en la necesidad de la realización de un estudio y una documentación del edificio, la conservación del mismo merced a una mínima intervención y a la distinguibilidad de la intervención respecto a las partes antiguas (1883). Estos principios se ampliaron sucesivamente: evitar las restituciones integrales y realizar una anastilosis, respetar de las diversas épocas históricas de la construcción, mantener el edificio en uso, respetar el carácter histórico y artístico, emplear una metodología multidisciplinar (1931); integrar la intervención dentro del respeto de la distinguibilidad (1932); dotar el edificio de una función útil y compatible y no añadir partes a la obra que no respeten lo existente (1964); tener en cuenta el papel del turismo y la puesta en valor del patrimonio (1967); conservar la pátina (1972); practicar la conservación integrada del edificio y el conjunto urbano, implicar la sociedad en la intervención (1975); defender la investigación científica, la formación, la participación social y la información, respetar la trama y el parcelado, los espacios urbanos y la población (1985); emplear los materiales, técnicas y oficios tradicionales

Arquitectónico (1975), Convenio de Granada (1985), Carta Internacional para la Conservación de las Ciudades Históricas (1987), Documento de Nara (1994), Carta de Burra (1999), Carta del Patrimonio Vernáculo Construido (1999), Principios de Conservación de las Estructuras Históricas en Madera (1999), Principios para el Análisis, Conservación y Restauración de las Estructuras del Patrimonio Arquitectónico (2003), Convenio del Patrimonio Inmaterial (2003), Declaración de Xian (2005), Declaración de Lima (2010). 
(1999); utilizar los materiales del contexto, actuar según el principio de la reversibilidad de la intervención y realizar actuaciones de prevención (2003); tener en cuenta y propiciar la necesidad de la gestión del patrimonio, así como la educación y la formación (2010).

El registro y la investigación de la cultura material ${ }^{4}$ para alcanzar un conocimiento histórico, objetivo central de la arqueología, constituye uno de los objetivos fundamentales también del estudio previo a la restauración necesario para entender y comprender el objeto arquitectónico y tomar las decisiones de un proyecto de restauración. Desde 1883, e incluso antes si se piensa en los estudios desarrollados por el propio Viollet-le-Duc, se aboga por un conocimiento amplio del objeto antes de la intervención. La multidisciplinariedad como requisito para un estudio sólido y completo aparece ya en la Carta de Atenas de 1931, aunque evidentemente el tipo de documentación e investigación ha ido cambiando y ampliándose en función de los avances de las propias disciplinas. El respeto de las diversas épocas de la construcción también está ya presente en 1931 y se reitera en todos los documentos hasta nuestros días. En las cartas de restauración, no aparece la referencia directa al término cultura material que, sin embargo, sí aparece en la Ley del Patrimonio Histórico Español (16/1985), que considera como su objetivo principal "asegurar la protección y fomentar la cultura material debida a la acción del hombre en sentido amplio, y concibe aquélla como un conjunto de bienes que en sí mismos han de ser apreciados, sin establecer limitaciones derivadas de su propiedad, uso, antigüedad o valor económico"s. El registro e interpretación del edificio y su transformación en el tiempo pasan por la realización de estudios históricos, arqueológicos, estratigráficos, constructivos, tipológicos, arquitectónicos, técnicos, estructurales, etc. La visión interconectada de todos estos aspectos permite

\footnotetext{
4 La noción de cultura material llega a su maduración en los primeros veinte años del siglo XX, aunque su gestación empieza ya en la segunda mitad del siglo XIX en el seno de diferentes corrientes de pensamiento que en ese momento se encontraban en un punto de convergencia. Un intento de definición de la noción de cultura material, fue brindado por los arqueólogos franceses Bucalle y Pesez (Bucaille y Pesez 1978) como la cultura de la colectividad cuyo estudio se centra en los fenómenos culturales, los fenómenos infraestructurales (la economía, la técnica, la producción) a través de los objetos materiales. En el editorial del primer número de la revista italiana Archeologia Medievale, publicado en 1974, la redacción precisa que, en ese contexto, arqueología medieval se entiende como "recogida de información a través de la recuperación sistemática de testigos materiales de la cultura post-clásica" de forma que a través de ella se pretende un acercamiento "a la historia de la cultura material" (Redacción de la revista, "Editorial", en Archeologia medievale, I, Clusf, Florencia, 1974, p. 7).

5 Cfr. España. Ley 16/1985.
}

una interpretación global que favorece el conocimiento del objeto, su valorización. La conservación de la cultura material como patrimonio histórico, cultural y social en una intervención debería constituir siempre una de sus prioridades. Tanto si se trata de un edificio monumental, como si se trata de un edificio residencial más modesto o una arquitectura vernácula, los avatares de la historia están impresos en su materia. Las huellas de los procesos constructivos y de las transformaciones, de las formas de trabajo y producción, de las intenciones y de los usos, constituye parte del patrimonio que se pretende conservar a la hora de plantear un proyecto de restauración arquitectónica ${ }^{6}$.

No siempre, por lo menos en el contexto español, la restauración incorpora mecanismos y acciones para la correcta conservación de las huellas materiales y esto sucede independientemente de que se haya realizado su estudio, registro y documentación e interpretación. Existe un salto entre el estudio del edificio y el proyecto de restauración. Los principios y criterios definidos en los documentos internacionales para la intervención deberían ser capaces de regular este salto, pero a menudo su aplicación se ve sujeta a las interpretaciones o tergiversaciones de los términos y los conceptos.

\section{ESTRATIGRAFÍA DE LA ARQUITECTURA Y RESTAURACIÓN}

A partir de finales de los años ochenta, como es bien sabido, se trató de conectar directamente la arqueología y la restauración y, en especial el análisis estratigráfico y el proyecto de restauración arquitectónica. Aunque no falten experiencias de interés en otros países, el contexto italiano aportó ya a partir de finales de los años ochenta, una reflexión específica sobre el tema. En 1987, Francovich abogó claramente por la colaboración entre la figura del arqueólogo, normalmente relegada a la fase de estudio y conocimiento previa al proyecto, y la figura del arquitecto restaurador, muy a menudo ocupado sólo

\footnotetext{
${ }^{6}$ Una experiencia de enorme calado a nivel peninsular constituye, desde hace décadas, el estudio desarrollado en la ciudad de Vitoria a partir de las excavaciones realizadas en la Catedral. La investigación realizada, además del estudio pormenorizado de las fábricas de la propia catedral, sus fases constructivas y el trabajo de los oficios, alcanza un profundo conocimiento de los inicios del asentamiento que dio origen a la ciudad de Vitoria y su evolución urbana, arquitectónica, social a través de los siglos. Esta experiencia constituye un importante avance en el conocimiento del yacimiento, pero también la puesta en valor de un patrimonio urbano y de arquitectura doméstica que supera con creces los confines geográficos de Álava. Esta investigación está ampliamente publicada en: Azkárate et al. 2001; Azkárate y Solaun 2013.
} 
de la fase proyectual ${ }^{7}$. En los años sucesivos, la investigación sobre el tema del papel que se debe asignar al análisis estratigráfico-constructivo en un proyecto de restauración fue abordada en este mismo contexto geográfico también por Brogiolo ${ }^{8}$ y Doglioni ${ }^{9}$.

Fue Doglioni quien, en una serie de publicaciones aparecidas sobre todo entre finales de los años noventa y principios del $2000^{10}$, defendió como arquitecto, la importancia de este tipo de estudio en relación con la conservación y la restauración del patrimonio arquitectónico. En sus escritos emergen importantes reflexiones ligadas a la concepción de la disciplina de la restauración como la conservación de la autenticidad del edificio ligada a la conservación de las huellas estratigráficas y la posibilidad de pensar en la obra de restauración como fase de estratificación intencional en el edificio. El análisis estratigráfico constituye una herramienta para leer e interpretar la historia del edificio, pero adquiere además un papel fundamental como herramienta formativa para el arquitecto restaurador en cuanto favorece lo que Doglioni define la mentalidad estratigráfica (Doglioni 1997).

El análisis estratigráfico aplicado a la arquitectura se ha desarrollado, en España, un poco más tarde que en Italia, según las afirmaciones de los propios protagonistas del debate (Caballero 1997). No es el objetivo de este artículo recorrer la historia de la introducción del método ${ }^{11} \mathrm{y}$ su aplicación a la restauración arquitectónica

\footnotetext{
Se trata de un tema que el mismo Francovich había ya expuesto varias veces en los años anteriores: Francovich 1982, 1985, 1988.

8 Cfr. Brogiolo 1993: 107.

9 Cfr. Doglioni 1990, 1993.

10 Además de una serie de artículos, véase Doglioni 1997, 2002.

11 Es amplia la experiencia española ligada al estudio de la arquitectura con métodos arqueológicos. En este sentido, destaca el trabajo constante desarrollado por Antonio Almagro, arquitecto y profesor investigador de la Escuela de Estudios Árabes del CSIC que, desde hace décadas, emplea los métodos arqueológicos para el estudio de la arquitectura. También, es bien conocida la actividad de los diferentes investigadores o grupos de investigación que desde un principio emplearon el método estratigráfico para el estudio de la arquitectura: el equipo dirigido por Alberto López Mullor del Servei de Catalogació i Conservació de Monuments de la Diputación de Barcelona; el equipo del CSIC dirigido por Luis Caballero Zoreda que, aunque se centre particularmente en estudios de tipo histórico-arqueológico, colabora con arquitectos para estudios previos a intervenciones en el patrimonio arquitectónico; el equipo, dirigido por el catedrático de la Universidad del País Vasco Agustín Azkárate, que ha desarrollado una importante labor de investigación en la provincia de Álava y que ha contribuido ampliamente a la difusión del método impulsado por la revista Arqueología de la Arquitectura. Desde los años noventa, un trabajo específico sobre el papel de la arqueología de la arquitectura en la rehabilitación ha sido desarrollado por Miguel Ángel Tabales de la Universidad de Sevilla. Entre otros: Tabales 1997, 2002a. Para más detalles sobre sobre el desarrollo de la Arqueología de la Arquitectura en España véase: Quirós 2002; Utrero 2010; Azkárate 2013. Un artículo también importante para entender el desarrollo de la arqueología de la arquitectura en España y en especial en Cataluña es: López Mullor 2010.
}

en España, pero quizás merece la pena realizar una reflexión al respecto. Es evidente que, en España al igual que en otros países, la arqueología como disciplina se había ocupado desde siempre del estudio de la arquitectura y las técnicas constructivas como parte del estudio del propio yacimiento arqueológico. Sin embargo, como en otros países europeos (entre ellos Italia, Francia, Reino Unido, Alemania, etc.) el nombre específico de arqueología de la arquitectura y la aplicación del método del análisis estratigráfico a los edificios empezaron a aparecer en los congresos de restauración sobre todo desde finales de los años noventa (López Mullor 1998) y a principios del 2000 (González Moreno-Navarro 2002) gracias a la implicación que la arqueología empezó a tener directamente en las obras de restauración del patrimonio arquitectónico. Un evento de gran importancia dentro de panorama español fue el Seminario Internacional Arqueología de la Arquitectura realizado en Vitoria en $2002^{12}$ donde arqueólogos y arquitectos estuvieron debatiendo, entre otros temas, sobre la relación fundamental entre arqueología y restauración.

A partir de ese momento, el estudio estratigráfico de la arquitectura, a pesar de carecer todavía de un nombre consensuado y de ser a veces no comprendido por algunos arquitectos que revindican la superioridad de la interpretación constructiva y estructural de la arquitectura ${ }^{13}$, entró a ser parte de una metodología reconocida como válida para el estudio de la arquitectura ${ }^{14}$.

12 Las actas del Seminario han sido publicadas en el primer número de la revista Arqueología de la Arquitectura (2002). En el segundo número de la misma revista (2003), se recogen los contenidos de algunos de los pósteres presentados en la sesión correspondiente del seminario. Cfr. AA. VV. 2002; 2003a.

13 Cuando, sobre todo a partir de finales de los años noventa, el método estratigráfico empezó a emplearse como una de las metodologías para el estudio del patrimonio arquitectónico, algunos arquitectos, quizás poco conocedores del método en profundidad, lo contrapusieron con otros tipos de estudios, como los constructivos y estructurales, sin entender las posibilidades de su complementariedad. La crítica se centró en el hecho que el análisis estratigráfico se realizaba en los muros de los edificios y su representación era plana y no tridimensional (Jiménez y Pinto 2003), absurdamente, no obstante, la representación cartesiana de un edificio (plantas, alzados, secciones) es la forma de representación común de la arquitectura y no es exclusiva de la estratigrafía. Por otro lado, se expresaron importantes precauciones en el empleo del análisis estratigráfico como método que puede inducir a intervenciones de restauración ligadas a la "estética matérica" que prima el fragmento, el contraste y la descontextualiza (Noguera 2002). Son estos solo algunos ejemplos de las críticas que el método estratigráfico recibió principalmente de parte de los arquitectos y en sus inicios. En la actualidad, el método parece estar ya más aceptado por el mundo de la arquitectura que, sin embargo, sigue teniendo un gran desconocimiento del mismo.

14 Muestra de ello es la publicación, sobre todo en Italia, de diversos manuales sobre el tema. Tras la publicación del libro de Doglioni, Stratigrafia e restauro, en 1997, se han publicado otros manuales con mayor o menor 
Su aplicación, aunque ya reconocida, sigue siendo poco difusa o a menudo desligada del proyecto de restauración o relacionada con la intervención solo en cuanto oportunidad para acceder directamente a los datos. A esta separación ha contribuido sin duda la segregación disciplinar. La arqueología de la arquitectura se ha quedado como una parte muy específica y minoritaria de la disciplina de la arqueología y en su mayoría son los arqueólogos los que se ocupan de ella, a pesar de que el objeto de estudio sea la arquitectura. De hecho, son todavía pocos los arquitectos españoles que tienen interés por la disciplina y sus métodos y que emplean el método estratigráfico sistemáticamente ${ }^{15}$. Basta recorrer las páginas de la propia revista Arqueología de la Arquitectura para confirmar que muy pocos artículos tratan de la arqueología de la arquitectura con directa referencia e implicación en la restauración arquitectónica ${ }^{16}$. Por el contrario, en muchos casos, se han empleado los métodos de la arqueología para aportar avances en la comprensión de las técnicas constructivas o la elaboración de cronotipologías que, como fuente de conocimiento, aportan una base para la conservación de la arquitectura ${ }^{17}$.

La mayoría de los artículos presentan solo la parte de registro e interpretación, realizados casi siempre en ocasión de una intervención, pero no abordan el problema de la conservación de esa misma materia que es la arquitectura. Al parecer, el estudio multidisciplinar, tan apreciado y necesario para la correcta comprensión del edificio, todavía no es capaz de generar verdaderos resultados si el proyectista o el grupo de proyectistas

éxito: Boato 2008; Alagna 2008; Beltramo 2009. En España, además de los artículos publicados en la revista Arqueología de la Arquitectura, habría que recordar algunos manuales (Tabales 2002b) y las actas de algunos encuentros que trataron de forma específica el tema (entre otros: Martín y Vega 2010).

15 En este sentido se debe de destacar la presencia activa de Antonio Almagro tanto en el Comité Científico de la revista Arqueología de la Arquitectura, así como autor de numerosos artículos sobre la historia y la interpretación arquitectónica de la arquitectura islámica. Entre otros: Almagro 2008a, 2008b. Desde las primeras experiencias realizadas en España, han estado presentes los arquitectos Leandro Cámara y Pablo Latorre (numerosos son sus artículos y contribuciones al respecto sobre todo en los primeros años del debate). Entre otros: Caballero Zoreda y Cámara Muñoz 1995; Latorre 1988; Latorre y caballero 1995. Por otro lado, los autores de este texto, desde 1998 aplican activamente el método de la lectura estratigráfica tanto como método de estudio (véase sus contribuciones en el número 2 de la revista Arqueología de la Arquitectura) así como herramienta útil para la reflexión y el planteamiento del proyecto: Mileto y Vegas 2004; Mileto 2006.

16 Entre otros: López Osorio y Torres Carbonell 2008; Squassina 2008; Cámara 2010.

17 Entre todos: Graciani y Tabales 2008; Cristini 2008; Vargas Lorenzo 2013; Canivell y Graciani 2015. no comprende y no integra todas las piezas del puzle en el proyecto de restauración. Realizar un estudio con métodos y resultados que no se acaban de dominar no permite su verdadero aprovechamiento. En este sentido, es fundamental la labor de formación de los futuros arquitectos independientemente de si serán los que finalmente realicen el estudio. Se trata de contribuir a la formación de la mirada del arquitecto como una mirada abierta y capaz de integrar las aportaciones que provienen de diversas disciplinas. En la actualidad, en España existen muy pocas escuelas de arquitectura donde la materia de la restauración arquitectónica se imparta de forma específica y obligatoria. En la mayoría de escuelas de arquitectura, la materia solo se imparte de forma optativa o se relega a la formación específica de postgrado en los másteres de especialización (Mileto et al. 2008). Por ello es interesante la experiencia que se ha llevado a cabo desde 2005, en la Escuela Técnica Superior de Arquitectura de la Universitat Politècnica de València donde se imparte una asignatura obligatoria de Restauración Arquitectónica. En esta asignatura, los estudiantes tienen que desarrollar un estudio completo de un edificio (estudio histórico y de contexto, levantamiento métrico, estudio de materiales y técnicas constructivas, estudio estratigráfico, estudio de degradación material y problemas estructurales) para poder redactar un proyecto de restauración del mismo (Mileto et al. 2008). Los futuros arquitectos aprenden que la lectura estratigráfica es parte de la metodología de estudio que permite alcanzar un mayor conocimiento del edificio antes de redactar un proyecto. Pero sobre todo aprenden a mirar la arquitectura como un objeto estratificado, fruto de los avatares de la historia, de las transformaciones debidas a las necesidades, así como a entender que cada acción de intervención, restauración y conservación deja una huella en la materia. Las intervenciones del pasado dejaron huellas a través de acciones de demolición y construcción (acciones negativas y positivas) de la misma forma que las intervenciones que se proyectan en la actualidad dejan huellas en la materia de la arquitectura, añaden o eliminan materia (Doglioni 2008), y en definitiva transforman el documento que se acaba de estudiar, documentar y conocer. Por otra parte, entre las experiencias docentes ligadas a la formación de los técnicos de la edificación en la disciplina de la arqueología de la arquitectura cabe destacar sin duda la importante labor que Miguel Ángel Tabales viene desarrollando desde hace tiempo en la escuela de Arquitectura Técnica en la Universidad de Sevilla. 


\section{CUATRO CASOS DONDE LAS MIRADAS SE CRUZAN}

La arquitectura es un objeto inanimado, evidentemente mudo, pero la mirada (Mileto 2006) de quien la estudia le proporciona vida a través de la interpretación de las señales y de los mensajes que estas proporcionan. El proyecto de restauración se genera a partir de esta mirada científica, que estudia y trata de entender científicamente el objeto, pero también se alimenta de la mirada como percepción $n^{18}$, que permite que el hombre perciba la arquitectura como un fragmento o como una unidad, como un conjunto de texturas y colores, y que en el ámbito de la restauración permite entender la teoría de las lagunas ${ }^{19} \mathrm{y}$ del fragmento. O de la mirada cultural ligada a los estímulos culturales del momento (Dorfles 1958) que se han visto reflejados en las diversas teorías de la restauración a partir del siglo XIX o en la apreciación del paso del tiempo como un valor añadido. O también la mirada sensible que permite alcanzar un conocimiento intermedio entre razón y sentimiento ${ }^{20} \mathrm{y}$ permite sentir la fuerza expresiva de las personas que construyeron, habitaron, transformaron la arquitectura, los hechos que ocurrieron. El proyecto de restauración no es por tanto el producto unívoco de unos factores científicos, es inevitablemente el producto de un conjunto de miradas y de factores culturales que difícilmente pueden producir una solución única. Cada proyecto es inevitablemente el fruto del conjunto de los datos científicos y de las miradas y, por ello, en cada ocasión se abre la posibilidad hacia nuevos caminos de investigación e interpretación. Por otra parte, la obra de restauración actúa en un bien patrimonial que materializa la cultura, la historia, la identidad y la herencia de un colectivo, por lo que su restauración o conservación tiene unas consecuencias que exceden las visiones personales y atañen a un colectivo. Por esta razón, los organismos internacionales, como se ha expuesto al principio de este texto, han ido definiendo una serie de principios irrenunciables como la investigación como fundamento de la intervención, la conservación de la materialidad y la

\footnotetext{
18 Es muy amplia la bibliografía relacionada con la teoría de la percepción, entre ellos: Koffka 1935 [1970]; Köhler 1947 [1961]; Arnheim 1954 [1979].

19 Consideremos en este sentido las teorías de Cesare Brandi, Umberto Baldini, Paul Philippot, etc.: Brandi 1963; Philippot 1972; Baldini 1978.

20 En este sentido se tienen que nombrar algunos autores que se ocupan de este tipo de experiencia como María Zambrano, Franco Rella, Eugenio Trías o el propio Walter Benjamin: Zambrano 1987; Rella 1990; Trías 1991; Benjamin 1994.
}

autenticidad, la mínima intervención, la distinguibilidad de la intervención, la conservación de las diversas fases de la estratificación, el empleo de materiales y técnicas compatibles, etc.

Los cuatro casos que se presentan a continuación, no se ofrecen como ejemplos paradigmáticos, sino como casos que permiten mostrar posibles puntos de contacto, colaboración y relación entre la arqueología y la concepción y la realización de una restauración de un edificio o conjunto histórico: casos donde la mirada cientifica se entrecruza con las miradas perceptiva, cultural y sensible para responder a diversas situaciones y necesidades. Las reflexiones que siguen están dirigidas sobre todo a los arqueólogos y arquitectos que operan en el campo y que pueden encontrar en la colaboración de las dos disciplinas un punto de fortalecimiento de sus propias actuaciones. No siempre, desgraciadamente, los arqueólogos participan de las decisiones del proyecto y la obra de restauración. De este modo, a menudo quedan ajenos a las necesidades que conlleva la consolidación de las fábricas, la accesibilidad y funcionalidad de los edificios, etc., así como a las torturadas decisiones que a veces se tienen que tomar en la obra o a los esfuerzos que se invierten para conservar y mantener al máximo las huellas de la historia constructiva del edificio, así como las modalidades operativas que se pueden emplear en este proceso. Por otro lado, los arquitectos no siempre participan del interés de la interpretación de los datos materiales que ofrecen las fábricas y de la oportunidad que estos datos y huellas pueden añadir a sus proyectos y obras.

Los cuatro casos que se presentan abarcan intervenciones desde rehabilitación de una sala en la Alhambra, hasta la recuperación de unos restos arqueológicos para un jardín público, pasando por la rehabilitación de una humilde vivienda. El último caso muestra también el peligro del prurito del conocimiento y su conflicto con la conservación. Las cuatro intervenciones son diferentes entre ellas porque los objetos y las metas mismas han sido muy diversos, pero todos ellos se rigen por el reconocimiento de la autenticidad de la materia del patrimonio arquitectónico como uno de los valores irrenunciables del mismo. Para el estudio de cada objeto se ha empleado diferentes herramientas ajustadas a los diversos casos, pero siempre persiguiendo los objetivos del conocimiento, de la conservación de la materialidad y de la puesta en valor del patrimonio arquitectónico en la actualidad como documento de la historia y como experiencia de identidad y cultura. 


\subsection{La sala lateral del Mexuar en la Alhambra}

La sala denominada "Barbería" se encuentra colindante al Mexuar en los palacios nazaríes de la Alhambra. Los autores de este artículo estuvieron desarrollando en este espacio un trabajo en varias fases que abarcaron desde el estudio estratigráfico de las fábricas y un estudio histórico y arqueológico, hasta el proyecto y la obra de rehabilitación del espacio para el uso de oficina, pasando por la consolidación y restauración de las fábricas y estructuras de la sala. El estudio estratigráfico, compuesto por la lectura de la UE y las relaciones estratigráficas y su periodización, se realizó conjuntamente con un estudio de los materiales y técnicas constructivas basado en la catalogación de estos elementos y el análisis granulométrico y caracterización de los morteros.

El estudio desarrollado (Vegas y Mileto 2010) evidenció la complejidad de la estratificación de la sala y de diversidad de las configuraciones que había adquirido a lo largo de los siglos tras las diversas operaciones de ampliación y transformación. Emergió así una Alhambra estratificada, plural y compleja que se reflejaba en una habitación de solo $70 \mathrm{~m}^{2}$. En la sala, se identificaron cinco periodos constructivos que se identificaron gracias al apoyo de la documentación histórica de archivo con cinco grandes momentos de la historia del conjunto (Fig. 1).

El primer periodo, que correspondiente a las obras realizadas entre mediados del siglo XIV y finales del siglo $\mathrm{XV}$, se ha identificado en los restos de una jamba policroma actualmente embutida en la parte este del paramento norte (una fábrica de ladrillo de color rojo oscuro recibida con un mortero de tierra y recubierta con un guarnecido de yeso con una franja policromada), en las fábricas que se encuentran en la parte superior del paramento este y ligadas al gran arco que se encuentra en el mismo y que conserva la cara interior de dos capiteles de yesería. Las huellas de este periodo hacen pensar que se tratara de una estancia interior de cierto calado.

El segundo periodo (1492-1528), que corresponde a las obras de adecuación de los palacios realizadas desde la entrada en Granada de los Reyes Católicos hasta los primeros años del reinado de Carlos $\mathrm{V}$, se manifiesta en
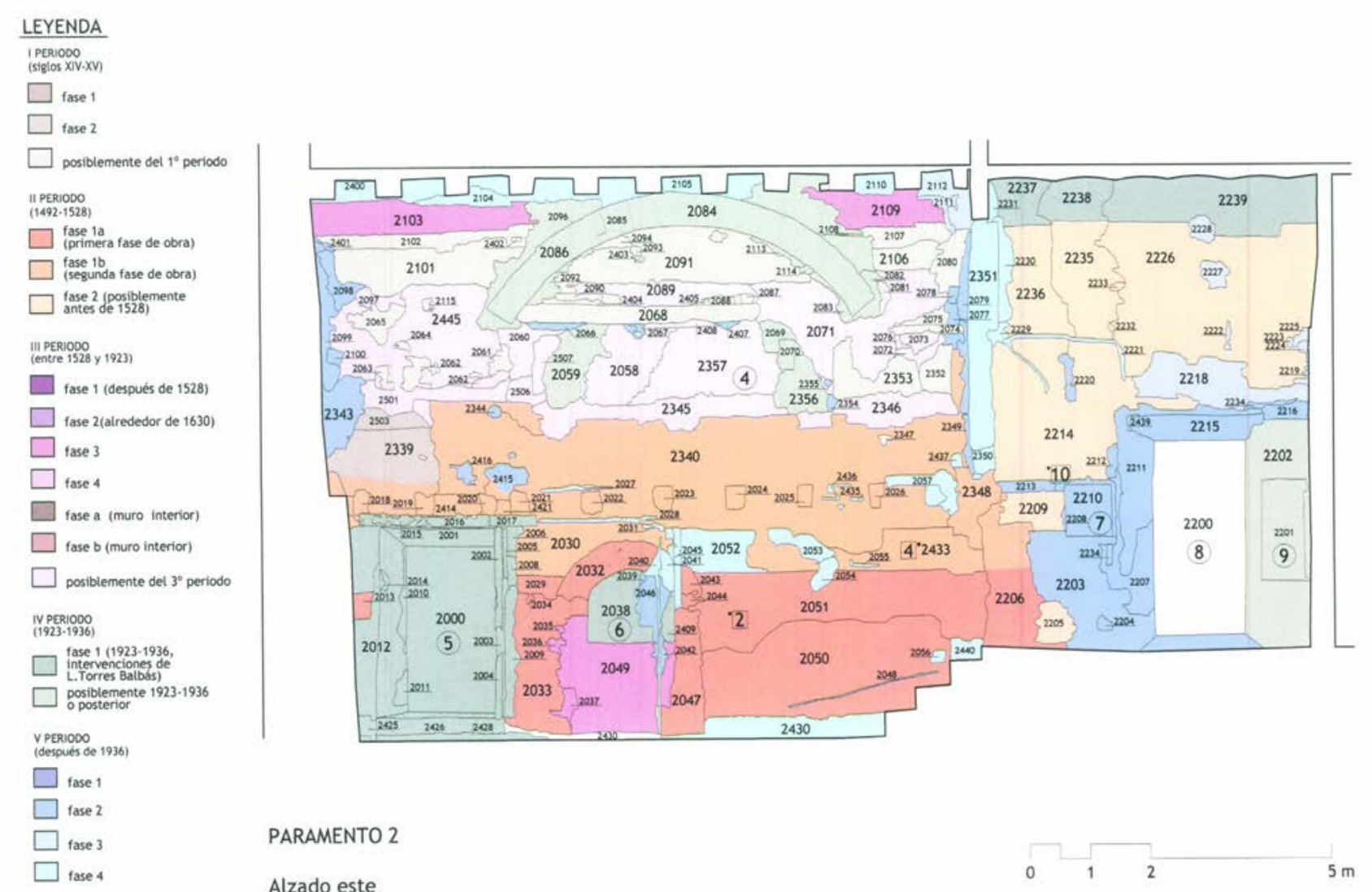

PARAMENTO 2

Alzado este

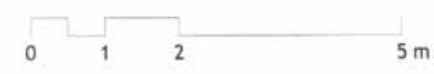

Figura 1. Hipótesis de las fases constructivas de la Sala de la Barbería (Palacios Nazaríes, Alhambra, Granada). Alzado interior del muro este. Autores Mileto y Vegas. 
las fábricas de ladrillo de la mitad inferior de los paramentos este, oeste y en el muro que divide la sala. En este mismo periodo, también se construyó el paramento adosado por el sur al paramento este del cuerpo principal de la sala, creando posiblemente un patio exterior adosado a la sala ya existente. En este segundo periodo es cuando la sala principal adquiere una configuración parecida a la que actualmente podemos ver, mientras que la sala pequeña todavía era un espacio abierto.

El tercer periodo (1528-1923), sin claras referencias históricas, consiste probablemente en una suma de acciones de mantenimiento y transformación ligadas al periodo de abandono de los palacios y su ocupación más o menos estable por diversos tipos de ocupantes. En una primera fase (entre 1528 y 1626), se cerró el pequeño edificio adosado por el sur al cuerpo principal de la sala, puesto que la sala aparece como un patio abierto en el plano realizado en 1528 por el arquitecto Pedro Machuca (1490-1550) y se tiene noticia de la construcción del forjado en la parte superior de la sala de mayor dimensión ya en 1626. También corresponden a este periodo las fábricas que conforman la parte superior del paramento norte posiblemente derivadas de la fijación de la chimenea-altar realizada alrededor de 1630 en la capilla instalada en el Mexuar.

El cuarto periodo (1923-1936) está muy definido a nivel de datos históricos, ya que corresponde a las obras realizadas por Leopoldo Torres Balbás en esos años, que están ampliamente documentadas en su Diario de Obra y que se identifican claramente a nivel estratigráfico: apertura de vanos y tapiado de puertas, sustitución del forjado de la habitación meridional, etc. A este periodo corresponde una actuación importante de sustitución de los ladrillos del arco de descarga correspondiente al vano adintelado central del muro meridional. También existen una serie de otras actuaciones ejecutadas a posteriori según el proyecto del mismo Torres Balbás.

El quinto periodo corresponde a obras realizadas después de 1936 ligadas sobre todo a la adaptación del espacio para uso de sala de museo: el tapiado de diversos vanos, la apertura de otros y sobre todo la realización de diversos revestimientos del interior de las salas.

La compleja historia de esta sala, las sucesivas configuraciones, los elementos pertenecientes a diferentes momentos y periodos de la construcción se manifiestan en la actualidad en fragmentos no necesariamente relacionados entre ellos (Fig. 2). Tras barajar las diversas alternativas posibles (Mileto y Vegas 2004), el proyecto de restauración de esta sala partió del presupuesto de la conservación de la fragmentación y la complejidad. No

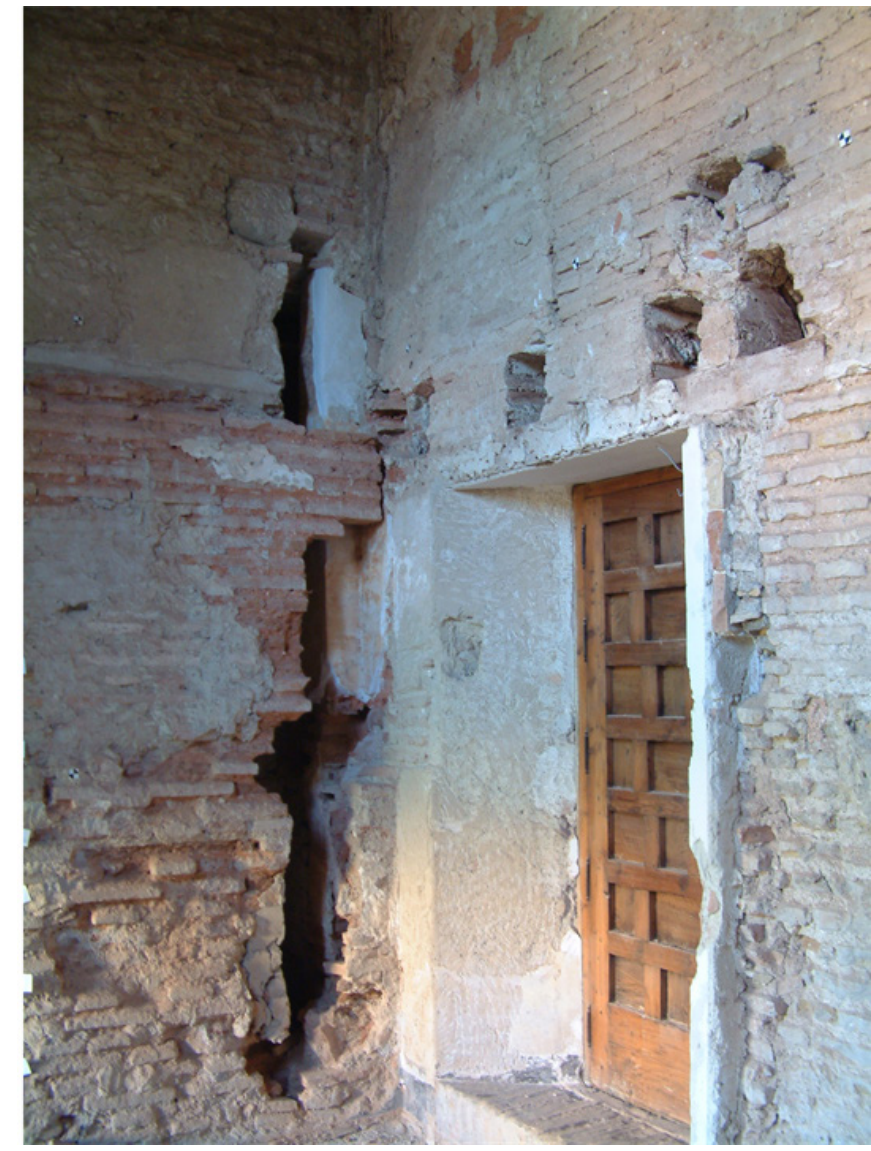

Figura 2. Esquina entre el muro este y el muro norte de la sala antes de la restauración. Sala de la Barbería (Palacios Nazaríes, Alhambra, Granada). Fotografía Mileto y Vegas.

se pretendió comunicar una configuración determinada y asociada a un momento concreto de la historia, y se consideró que el valor de la sala estaba precisamente en su capacidad de mostrar la historia compleja de la transformación continua, de la readaptación según el nuevo uso y según el gusto estético del momento. Además, el valor de la complejidad se consideró como un valor a preservar no solo ligado a la sala de la "Barbería" sino al conjunto entero de la Alhambra que, en esta estratificación casi impenetrable, tenía la ocasión de mostrar su autenticidad. Así el proyecto y la obra se dirigieron hacia la conservación de las fábricas, su reparación y consolidación estructural (Fig. 3). En algunos casos, tras reflexionar sobre el límite entre la pérdida de los datos materiales y la legibilidad y decoro del conjunto, se eliminaron algunos restos de elementos ya retirados antes de la intervención como instalaciones (algunas rozas generadas para alojar las instalaciones eléctricas se rellenaron con mortero manteniendo la huella), enfoscados (algunos parches de cemento en los muros) y 


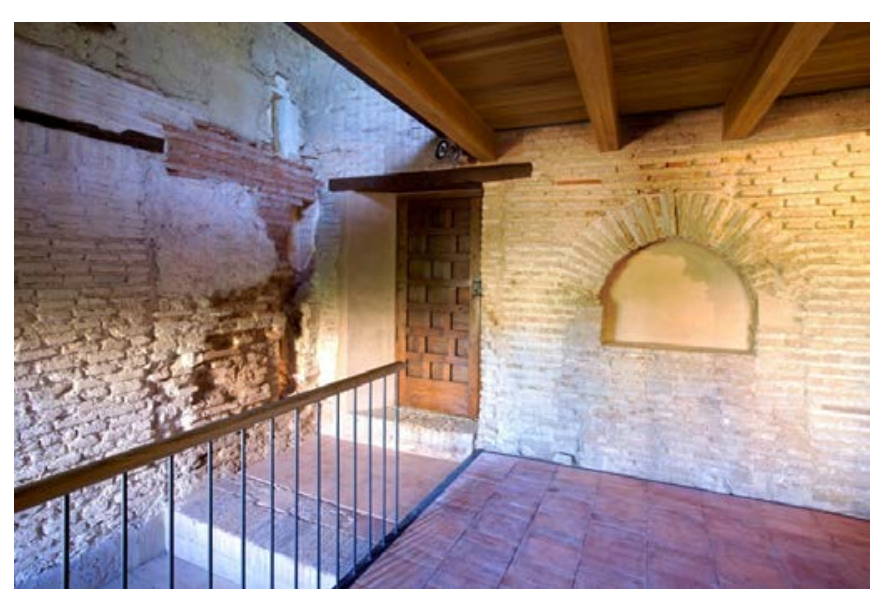

Figura 3. Esquina entre el muro este y el muro norte de la sala después de la restauración. Sala de la Barbería (Palacios Nazaríes, Alhambra, Granada). Fotografía Cristina García Zarza.

se perfilaron las jambas de las puertas que, tras el haber eliminado los enfoscados de cemento anteriormente al proyecto y las obras, se habían dañado o estaban desprendidas. En todo caso se han dejado las huellas de las intervenciones y se han rellenado las lagunas con un borde de apoyo que no enmascara el borde estratigráfico.

La fragmentación de las fábricas se integró posteriormente en un proyecto de rehabilitación del espacio destinado a oficina (Vegas y Mileto 2010). El objetivo principal de esta actuación ha sido la posibilidad de compatibilizar el uso cotidiano del espacio con la conservación de su estratificación (Fig. 4). Las nuevas estructuras introducidas, como el forjado intermedio y las dos escaleras, se plantearon como estructuras autónomas que contenían las instalaciones en su interior para no tener que crear nuevas rozas en los muros. Los materiales elegidos eran los tradicionales (baldosa de

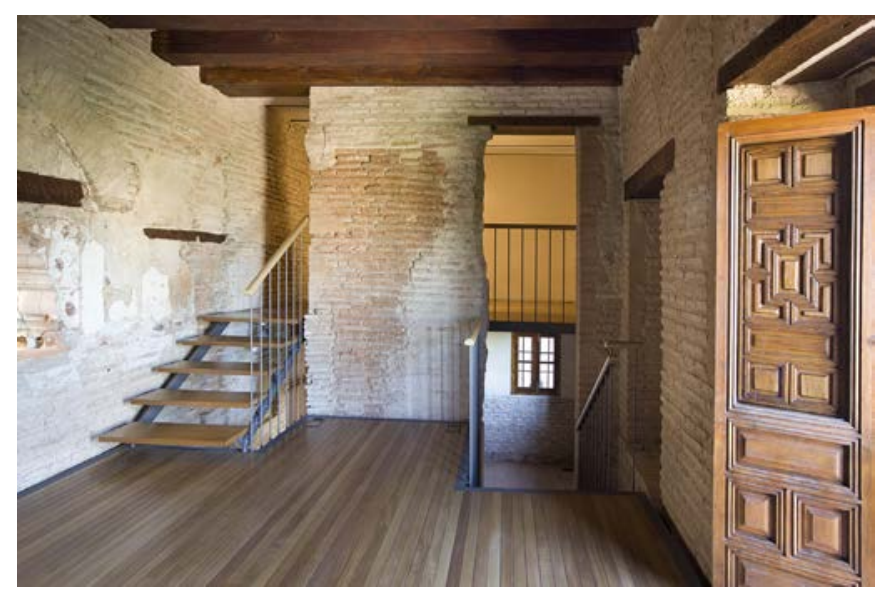

Figura 4. Imagen general del primer piso de la sala de mayores dimensiones tras la restauración. Sala de la Barbería (Palacios Nazaríes, Alhambra, Granada). Fotografía Mileto y Vegas. barro para el pavimento de la planta baja y madera para los forjados y las escaleras), pero distinguible por su diseño geométrico y modular, por la inserción de los finos perfiles metálicos que contenían las instalaciones.

\subsection{La recuperación de los restos del Convento de San Francisco en Vinaroz}

En el año 2001 el Convento de San Francisco de Vinaroz (Castellón) fue demolido por la municipalidad de forma deliberada con la intención de ocupar el solar derivado de la demolición por edificios de viviendas en altura. En el momento de la demolición estaba en trámite la declaración del conjunto como bien de interés cultural y su incauta demolición desencadenó una fuerte reacción por parte de la administración autonómica responsable de su protección que obligó a la municipalidad a destinar obligatoriamente el solar para uso público. Desde ese momento el solar, asfaltado sin más atención, se empleó como aparcamiento en superficie (Fig. 5). En 2014, la municipalidad, bajo insistente solicitud de los servicios autonómicos de patrimonio, decidió encargar un proyecto de ajardinamiento y evocación del antiguo convento.

El convento de San Francisco, construido en el siglo XVII, había sido desamortizado en el siglo XIX y utilizado como cárcel a partir de 1843 y hospital desde 1867 (Baila Pallarés 2012). Tras el saqueo de la iglesia durante la Guerra Civil, el convento se reformó para su uso como hospital, cárcel y palacio de justicia, y luego sede del ayuntamiento, de la policía municipal y de los servicios sociales. Tras un leve incendio ocurrido en 1975 y sobre todo los daños causados por la falta de

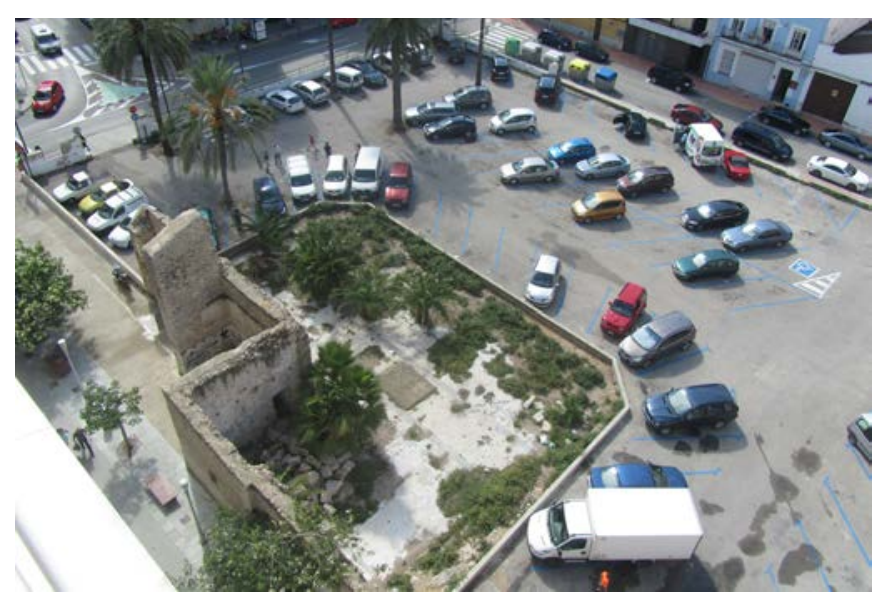

Figura 5. Solar del antiguo Convento de San Francisco, Vinaroz (Castellón) tras la demolición del convento. Fotografía Mileto y Vegas. 
mantenimiento, la iglesia se declaró en ruina en 1993. En 1999 se aprobó en el Pleno del Ayuntamiento el proyecto de demolición del conjunto que, pese a las advertencias del gobierno autonómico, se ejecutó en 2001. Tras su destrucción, quedó todavía en pie solo el muro norte de la iglesia porque, en el momento de la demolición, constituía la medianera de unas casas habitadas. Del resto del convento, lo único que quedó visible fue su interfaz negativa entre bloques de edificios nuevos (Fig. 6): un lugar vacío, sin cualidades y espejo del abandono, la degradación y la incultura patrimonial.

El cometido del proyecto, encomendado a los autores de este texto era la evocación de un convento que ya no existía y que, además, había sido destruido en circunstancias muy dudosas. La demolición había arrasado el convento y los sillares y restos que debían

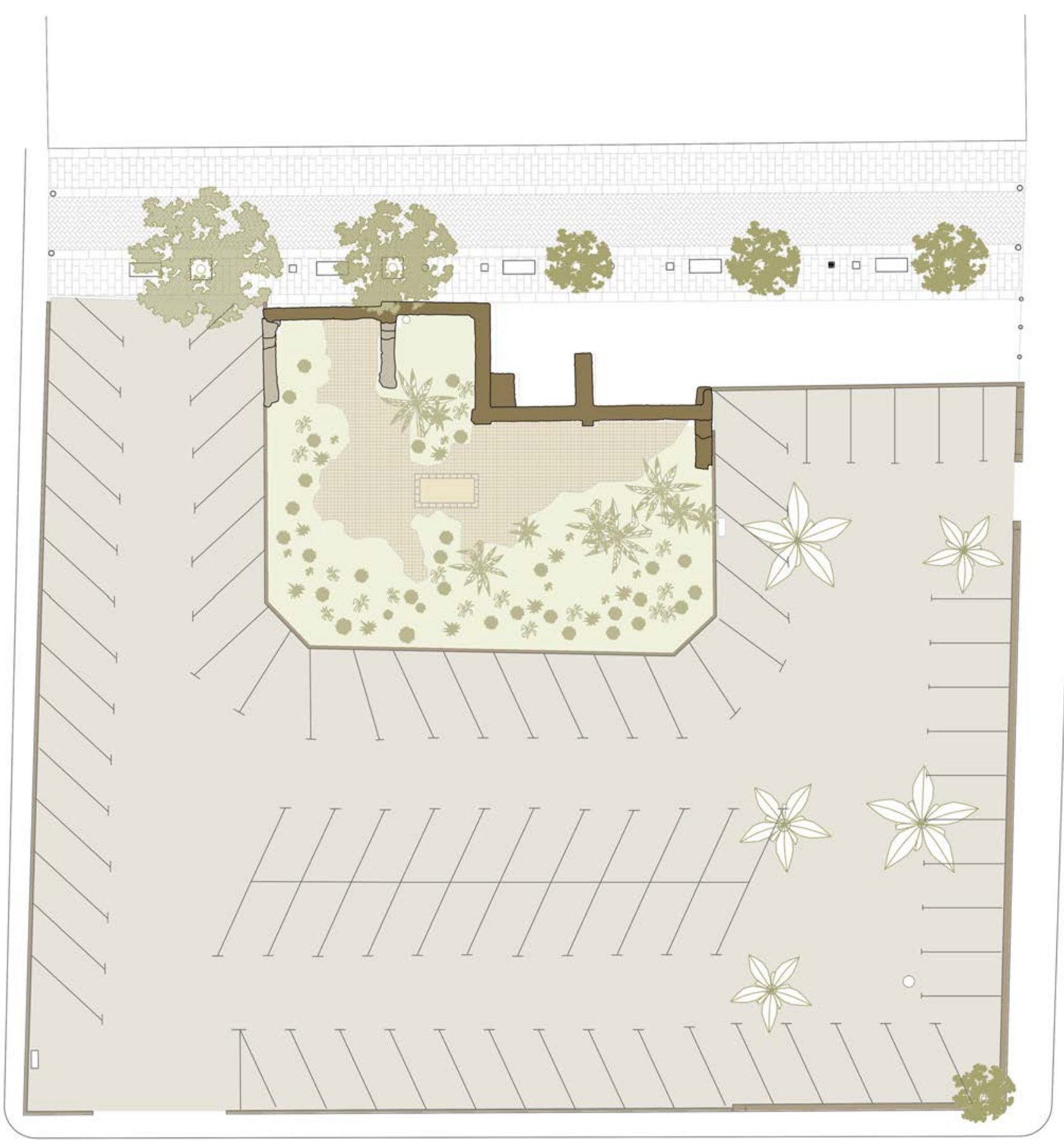

Figura 6. Plano del estado del solar del antiguo Convento de San Francisco, Vinaroz (Castellón) antes de la intervención. Autores Mileto y Vegas. 
haberse salvado tras la misma también se habían perdido en extrañas circunstancias. De las piedras del convento solo quedaban un escudo y la piedra fundacional, olvidados en una esquina de un jardín de carretera, y las lápidas antaño integradas en el pavimento de la iglesia que, para protegerlas tras la demolición, se habían arrancado de su situación original para acabar en el almacén municipal a la espera de un destino mejor. Dado el triste panorama de la situación, se decidió emprender el complejo camino de la recuperación de la memoria del convento a través de sus posibles huellas en el solar y de sus escasos fragmentos. Se tenía amplia constancia de las configuraciones que había tenido el convento en el siglo XX gracias a los planos existentes:

En primer lugar, se emprendió la eliminación del asfalto que, como una capa de olvido, cubría completamente el solar. La eliminación de este estrato se realizó con un

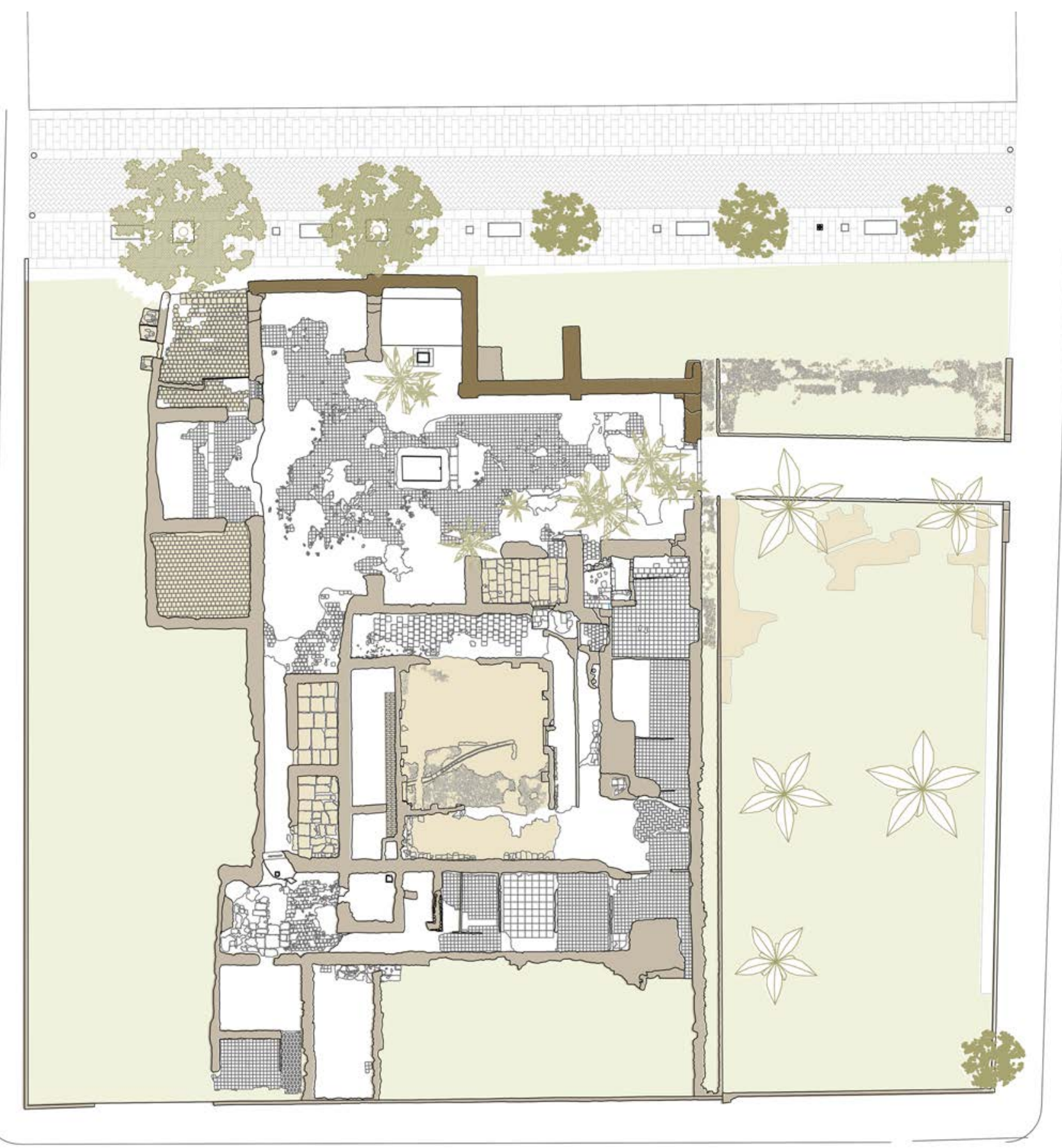

Figura 7. Plano de la excavación arqueológica realizada en el solar del antiguo Convento de San Francisco, Vinaroz (Castellón). Autores Mileto y Vegas; reelaboración del plano de: Sonia López Melón. 
atento seguimiento arqueológico ${ }^{21}$ (López Melón 2015). Emergió así la huella completa de la planta del convento (Fig. 7), aunque la altura de sus muros no pasaba de unos pocos centímetros. Estos muros con unos cimientos de mampostería todavía visible pudieron estar construidos en su día de mampostería encofrada y algún caso, quizás, de tapia. También aparecieron, debajo de la capa de escombros de la demolición, algunos pavimentos antiguos de losas de piedra caliza de grandes dimensiones (en una de las capillas de la iglesia y en dos espacios del claustro), de guijarros (en el camino de acceso y en el claustro) y de cerámica (los espacios anexos a la iglesia) y muchos pavimentos recientes ligados a los usos que el edificio había tenido hasta su demolición. El seguimiento arqueológico registró entre los escombros numerosos fragmentos de loza y cerámica vidriada de los siglos del XVII al XIX, así como fragmentos de vajilla del siglo XX. También se realizó un estudio arqueológico de las criptas encontradas bajo el nivel de la iglesia donde se estudiaron y catalogaron los restos de huesos humanos (López Melón 2015).

El espacio del claustro apareció perfectamente definido por el pavimento de guijarros, que se encontró prácticamente completo, el pozo central de planta circular y a los sillares de piedra caliza de las bases de los muros del perímetro que todavía permitían la perfecta identificación de los pilares del pórtico y los cuatro accesos que daban paso del pórtico centro del claustro. La iglesia estaba completamente definida en su planta por los muros perimetrales, las huellas de los pilares y, por supuesto, por el muro norte, que quedaba todavía parcialmente en pie con sus revestimientos y restos de policromías que, aunque muy deterioradas por la falta de mantenimiento y por su exposición a los agentes atmosféricos, podían todavía dar una idea de cómo tuvo que ser la decoración interior de la iglesia.

Tras el estudio y la intervención arqueológica realizada se planteó un proyecto dirigido a la recuperación de la memoria del convento ${ }^{22}$. La reconstrucción del conjunto se descartó desde el principio por dos razones principales: en primer lugar, la cantidad de restos materiales que quedaban en el solar se limitaba a los cimientos de los muros del antiguo convento y algunos pavimentos, por lo que la reconstrucción hubiese sido

\footnotetext{
21 Véase: López Melón, S. 2015: Memoria final de la intervención arqueológica realizada en las obras de la plaza jardín del antiguo convento de San Francisco Vinaròs, documento inédito.

22 El proyecto y la obra han sido galardonados con el segundo premio del Premio Internacional IQU-Riqualificazione Urbana (2016) y el primer premio del Colegio de Arquitectos de la Comunidad Valenciana (2017). La actuación está publicada con detalle en: Vegas y Mileto 2016; Mileto y Vegas 2016.
}

una mera reinterpretación del conjunto a través de planos y fotografías pero sin una base de restos materiales; en segundo lugar, la conservación del vacío provocado por la demolición pretendía mantener la memoria del convento a través del conjunto de su historia que desgraciadamente incluía su demolición como uno de los capítulos significativos e imborrables de la misma. Se planteó, por tanto, el proyecto de un lugar que fuera capaz de conjugar los aspectos materiales (la distribución en planta del convento, el muro norte de la iglesia, los cimientos de algunos muros, los pavimentos antiguos, los restos arqueológicos) e inmateriales (la memoria del lugar, el nuevo uso público como punición por la demolición realizada) en un "jardín de la memoria" que, como un cementerio inglés, fuera capaz de transmitir una sensación de paz a pesar de la pérdida.

El nuevo jardín (Fig. 8) surgió de los propios escombros de la demolición del convento que se recuperaron tras la excavación para aparejarlos en seco y conformar los bancos de asiento (Fig. 9). Estos muretes, de unos 70 $\mathrm{cm}$ de alto, se superponen a los restos de los muros del convento, protegiéndolos y a la vez recreciéndolos de forma que se pueda distinguir la parte nueva de la antigua. Todos los materiales empleados en esta operación (ladrillos, sillares de piedra, bloques de hormigón, baldosas cerámicas, baldosas hidráulicas, tejas, etc.) provienen de la demolición y representan en su conjunto desordenado los diversos periodos constructivos que configuraron el convento desaparecido (Fig. 10). La reutilización de los escombros en el mismo lugar representa una recuperación del material y un aprovechamiento de recursos, al tiempo que una recuperación de la memoria del convento. Los pocos pavimentos históricos que aparecieron tras la excavación, como se ha descrito anteriormente, se mantuvieron in situ y pisables, favoreciendo además la recuperación de los espacios significativos del convento como los accesos, el claustro y las estancias alrededor del claustro (Fig. 11). Los nuevos pavimentos, que se aportan para completar y reintegrar las superficies pisables, se emplean además para distinguir los espacios del resto del convento: un pavimento de losas de piedra con junta cerrada en toda la iglesia que sirve como espacio para concierto y espectáculos al aire libre, un pavimento de losas de piedra con junta abierta en el resto de los espacios del convento de forma que la hierba que crece entre las juntas cree una transición con los espacios ajardinados que se recuperan a partir de los propios huertos del antiguo convento. La mirada estratigráfica, en este caso, se materializa en diversos aspectos del proyecto: el estudio atento de los 


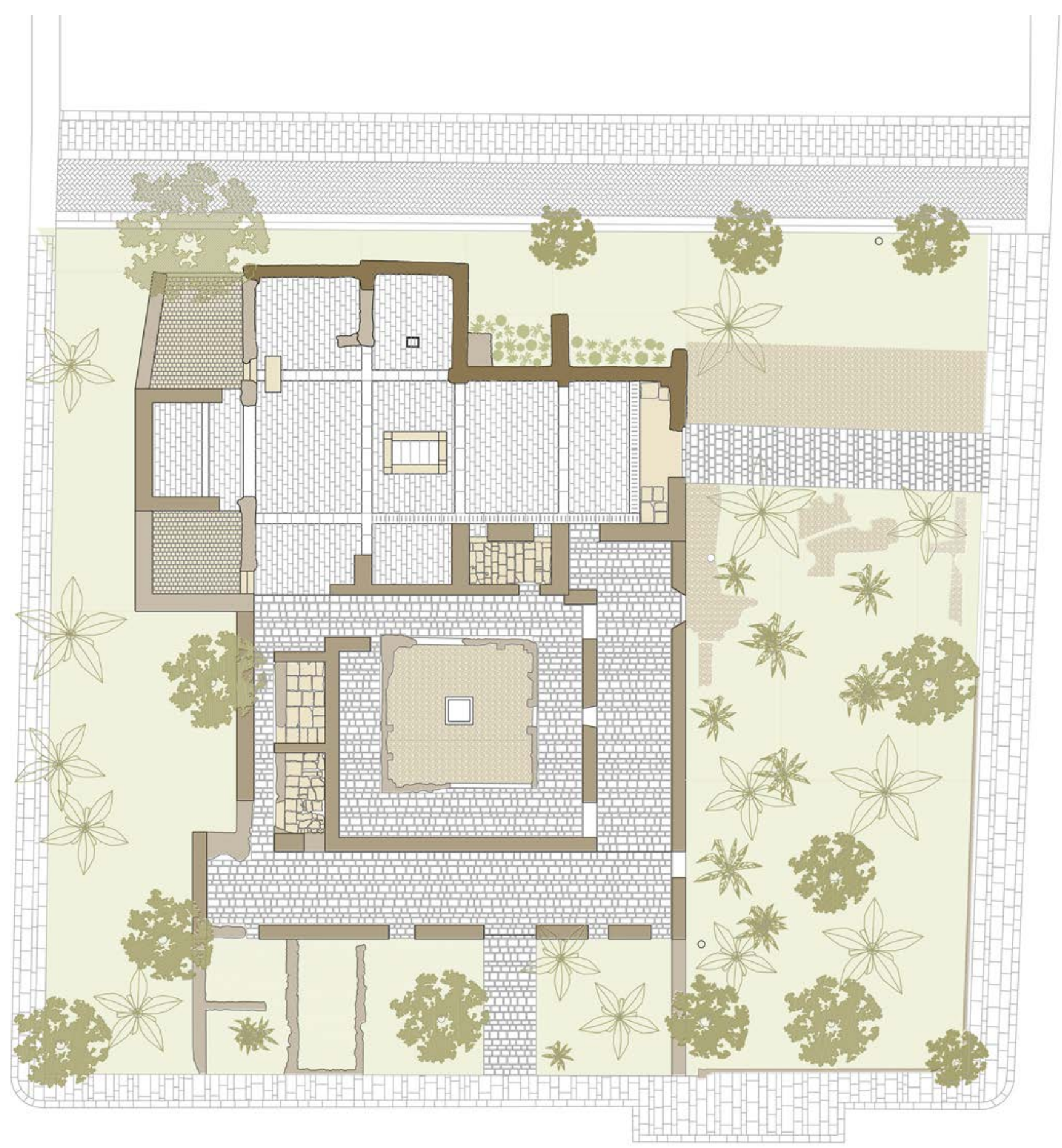

Figura 8. Plano del proyecto del Jardín de la Memoria en el solar del antiguo Convento de San Francisco, Vinaroz (Castellón). Autores Mileto y Vegas

restos aparecidos durante la excavación arqueológica (levantamiento, catalogación, estudio histórico y contextualización); la integración de los restos en el proyecto con la adaptación y revisión del proyecto en función de los restos; la búsqueda de la conservación de los pocos restos del convento (muros de la iglesia, arranques de los muros del resto de las fábricas, pavimentos históricos, etc.) y su puesta en valor en el conjunto como elemento activos de la memoria del lugar; el respeto material de los restos arqueológicos a través de la conservación de su extensión, su protección, su integración respetando los bordes estratigráficos; la idea de estratificación como leit motiv del proyecto que abarca desde los restos arqueológicos y arquitectónico hasta los nuevos elementos construidos. 


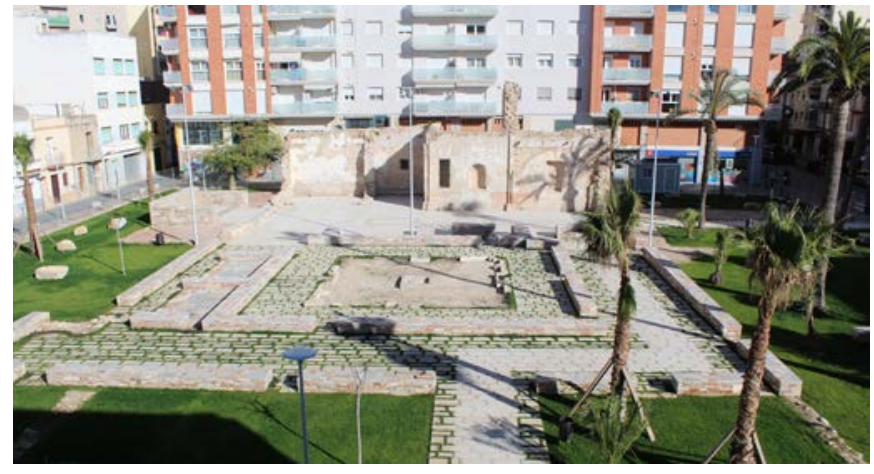

Figura 9. Vista general del Jardín de la Memoria en el solar del antiguo Convento de San Francisco, Vinaroz (Castellón). Fotografía Vicente Giménez.

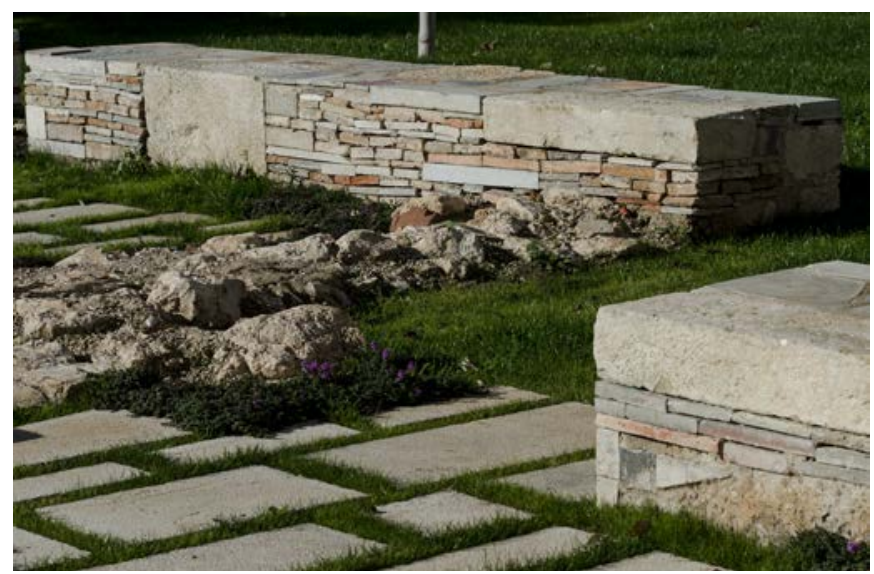

Figura 10. Detalle de los restos arqueológicos y lo nuevos muretes del Jardín de la Memoria, Vinaroz (Castellón). Fotografía Vicente Giménez.

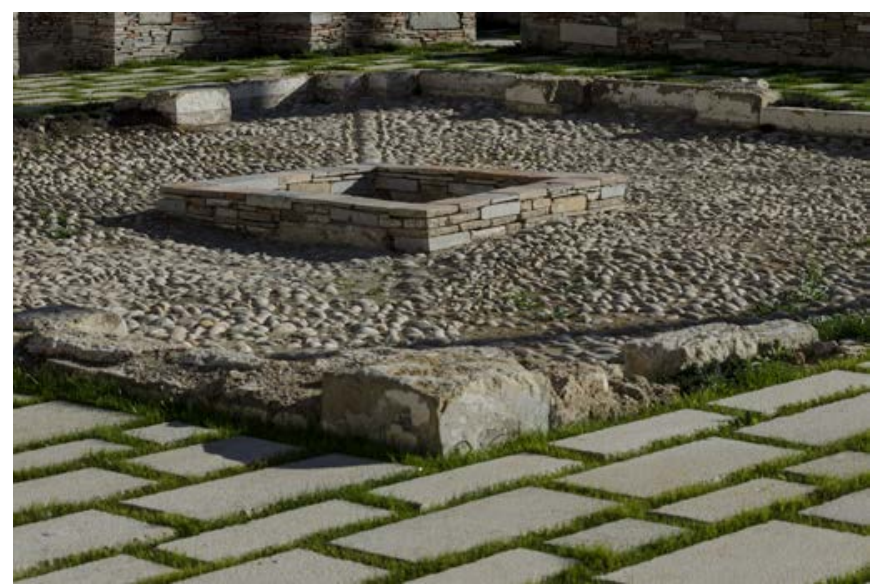

Figura 11. Detalle del pavimento y la base del pórtico del claustro del antiguo convento del Jardín de la Memoria, Vinaroz (Castellón). Fotografía Vicente Giménez.

\subsection{Edificio de viviendas en la calle Maldonado número 33}

El pequeño edificio de viviendas situado en la calle Maldonado al número 33 en Valencia era tan humilde e insignificante que no gozaba de ningún tipo de protección (Fig. 12). El edificio ocupaba un solar muy alargado y se abría a la calle principal con una estrecha fachada de un estilo academicista pobre y muy poco llamativo. El edificio, destinado a viviendas de alquiler en un barrio marginal del centro histórico de la ciudad, había sufrido unas intervenciones durante el siglo XX y, sobre todo, era víctima de la degradación y del abandono, por lo que estaba destinado a derribo para dar paso a edificación de nueva planta. Sin embargo, los autores de este texto consiguieron que se salvara el edificio y se pudiera rehabilitar gracias a un atento estudio de su materialidad y a la puesta en valor de la riqueza de periodos constructivos y transformaciones que se escondía tras un aparente edificio anónimo de finales del siglo XIX.

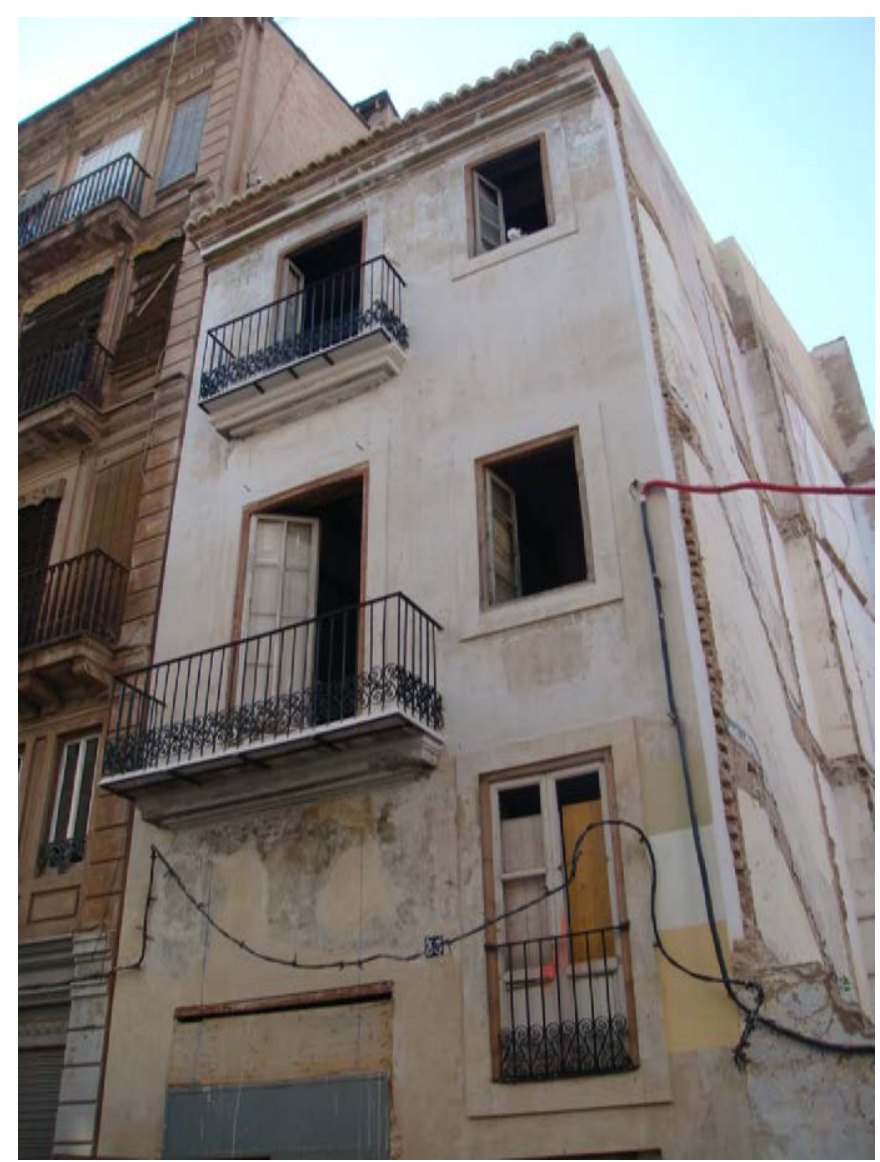

Figura 12. Edificio de viviendas en la Calle Maldonado 33 en el barrio de Velluters (Valencia) durante los trabajos de rehabilitación. Fotografía Mileto y Vegas. 
El edificio, en el momento que se desarrolló el estudio, estaba en parte enlucido por lo que, para la lectura e interpretación de las fases constructivas, se emplearon diversos métodos de lectura cruzada. Las interpretaciones se pudieron en parte confirmar durante la obra de restauración. Se realizó, por una parte el estudio histórico documental con un minucioso vaciado del archivo histórico municipal que proporcionó los datos históricos de las intervenciones realizadas a partir del siglo XIX y, por otra parte, el estudio de la materialidad del edificio mediante un preciso levantamiento métrico descriptivo, un estudio de materiales y técnicas constructivas, un estudio estratigráfico de las fábricas, un estudio cronotipológico de las fábricas, de los forjados y las cubiertas y un estudio de los problemas materiales y estructurales. Se catalogaron todas las fábricas de ladrillo (aparejos, tamaño de ladrillos, grosor y composición de los morteros, acabado de las juntas, etc.), las vigas, viguetas y revoltones de los forjados y las cubiertas (tamaños de los elementos y secciones, cortes y huellas de las herramientas, marcas de carpintero, dimensiones del entrevigado, apoyos, encuentros, acabados y policromías, etc.) (Fig. 13), los balcones y carpinterías exteriores e interiores. A través del levantamiento se detectaron anomalías geométricas que permitieron avanzar en la interpretación del edificio como desplomes, inclinaciones, irregularidades. La hipótesis de las fases de transformación del edificio se alcanzó gracias a la superposición de todos los datos históricos, estratigráficos, cronotipológicos, constructivos, etc.

A través de este amplio estudio (Mileto y Vegas 2015), se pudo entender que se trataba de un edificio del siglo XVI (correspondiente solo a las primeras dos crujías del edificio actual con un forjado con vigas de gran escuadría con bocel y amplios revoltones), ampliado en su parte trasera en el siglo XVIII con una primera planta (forjados con vigas menores con bocel y revoltones decorados con una cinta gris-azul esgrafiada) (Fig. 14) y una planta bajo cubierta que todavía conservaba su cubierta inclinada a pesar de la sobrelevación del piso superior. El edificio, en el siglo XIX, había sufrido una amplia remodelación, documentada a través de los proyectos encontrados en el Archivo Histórico Municipal de Valencia: una primera remodelación de la facha en 1864 (autor: arquitecto José
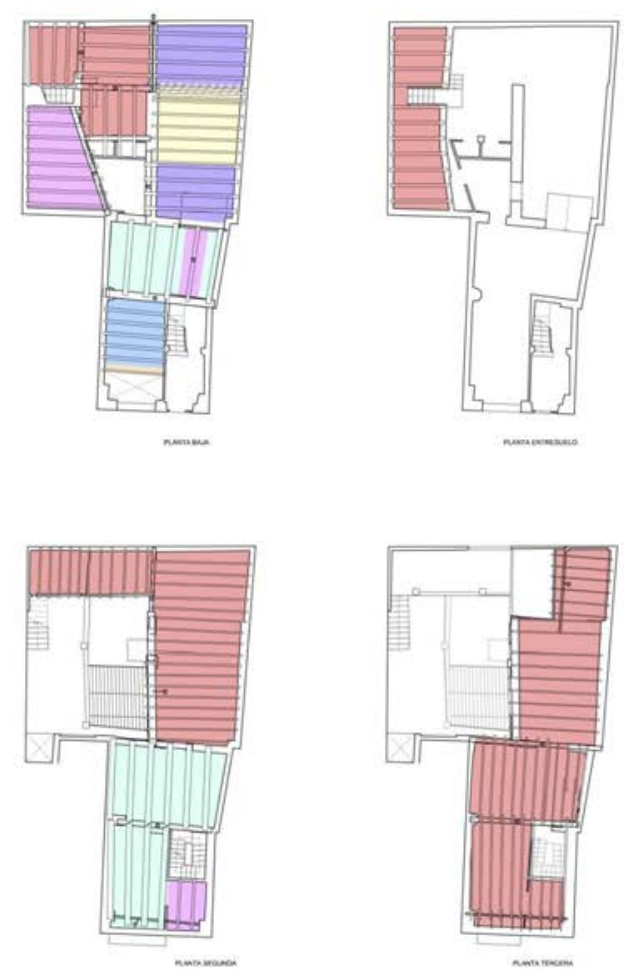
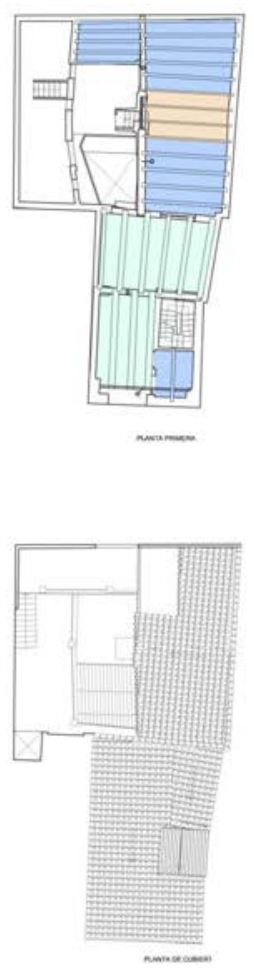
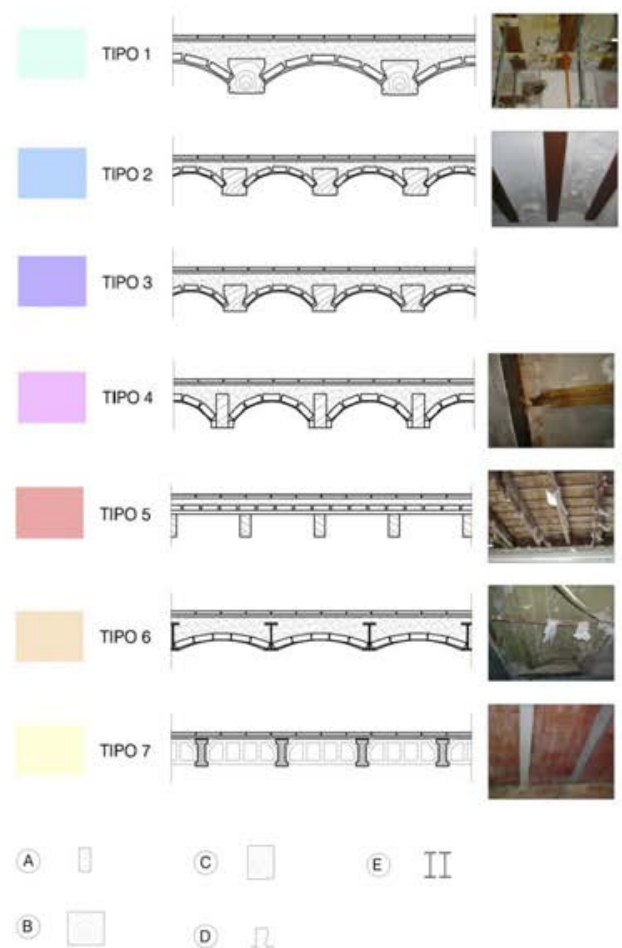

Figura 13. Estudio de los tipos de forjados históricos presentes en el edificio de viviendas en la Calle Maldonado 33 (Valencia). Autores Mileto y Vegas. 


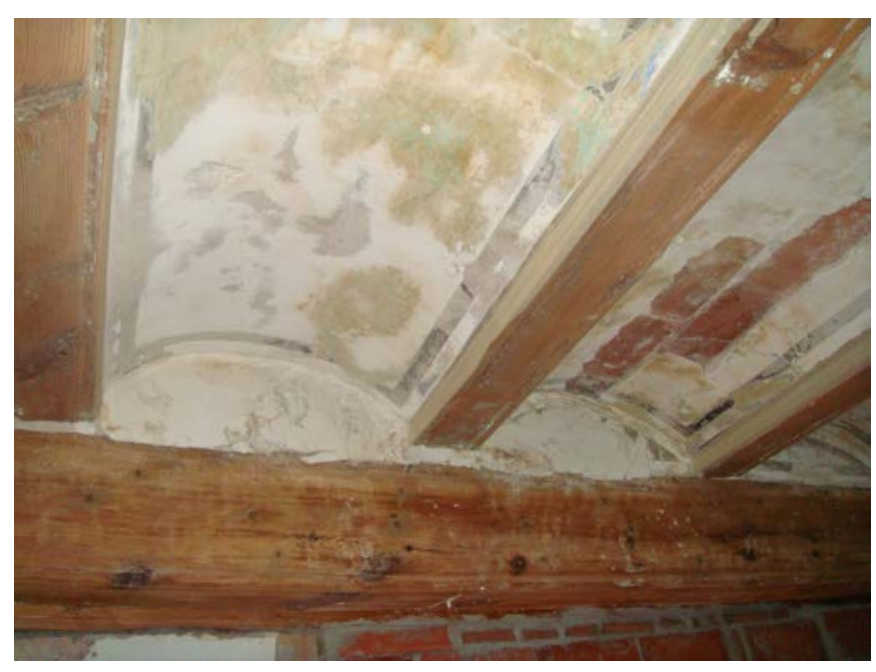

Figura 14. Forjado del siglo XVIII con decoración esgrafiada encontrado en la crujía trasera del edificio de viviendas en la Calle Maldonado 33 (Valencia). Fotografía Mileto y Vegas.

Serra; AHMV 1864) donde ordenan geométricamente los vanos de la segunda planta con los vanos de la planta inferior; y un proyecto para una nueva fachada en 1899 (autor: arquitecto Joaquín María Arnau; AHMV 1899), que responde a una operación de modificación de la alineación de las fachadas de todos los edificios de la calle tras el cierre de la antigua acequia que ocupaba parte de la calzada y el permiso concedido por la autoridad municipal de ocupar un metro más de vía pública frente al solar.

Esta intervención de traslado hacia delante de las fachadas explica el hecho que todas las correas de los forjados y cubierta recayentes a la fachada principal estén suplementadas en el último metro hacia la fachada. El arquitecto Arnau, a la hora de adelantar la fachada, no demuele el resto del edificio, sino que coloca una viga que, apoyada en dos ménsulas encajadas en la nueva fachada, soporta los antiguos forjados y cubierta (Fig. 15). Esta acción se acompañó del desplazamiento de la escalera desde su posición en fachada hacia la segunda crujía, dejando así la posibilidad de abrir una habitación más hacia la calle principal, y la sustitución de los pavimentos y carpinterías. En 1914, el edificio sufre una nueva intervención que conlleva la construcción de un piso más en la parte trasera.

En definitiva, tras unos acabados debidos a las últimas reformas del edificio entre finales del siglo XIX y la primera mitad del siglo XX (pavimentos de

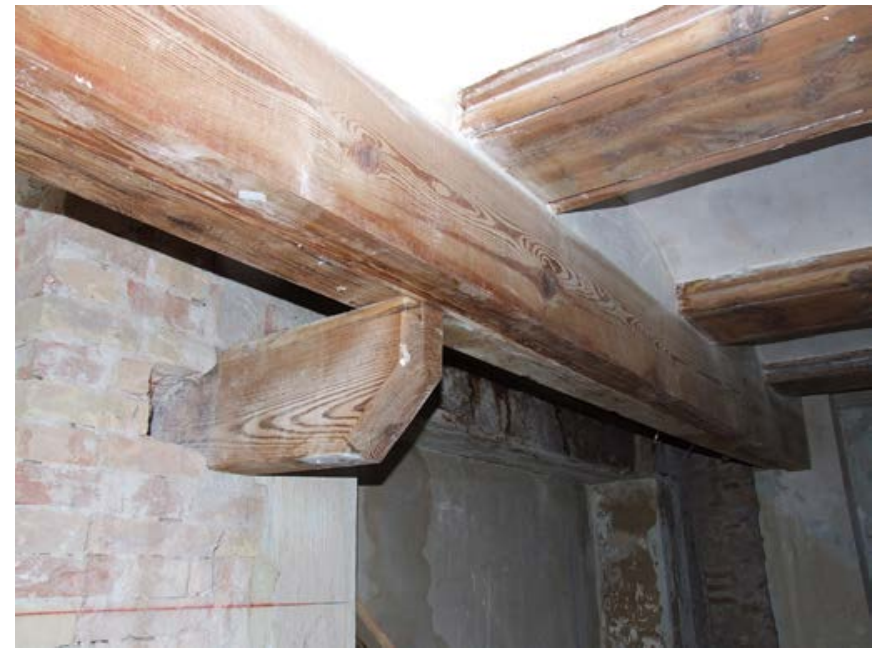

Figura 15. Viga paralela a la fachada que aguanta el forjado de la primera crujía del edificio de viviendas en la Calle Maldonado 33 (Valencia). Fotografía Mileto y Vegas.

baldosas hidráulica, falsos techos de cañizo, carpinterías de media caña, etc.), se escondían unas estructuras más antiguas y a su vez estratificadas (muros, forjados, cubiertas, etc.) que elevaban el edificio a un verdadero testigo de la historia construida del tejido residencial de la ciudad de Valencia (Figs. 16 y 17). Tras el estudio realizado, el pequeño edificio de la calle Maldonado, destinado a derribo por su insignificancia, se reconoció como edificio de valor por la municipalidad y se rehabilitó, dentro de una operación más amplia (Mileto y Vegas 2014), como edificio de viviendas de promoción oficial. Con la clara intención de transmitir el pequeño edificio con toda su carga histórica, en la obra realizada, se mantuvieron todas las fábricas y las huellas estratigráficas (aunque enlucidas con yeso en el interior de las viviendas), se conservaron todos los forjados históricos respetando las diferencias, los desniveles, las respectivas decoraciones; se mantuvieron las huellas del desplazamiento de la fachada legibles en las vigas paralelas a la misma en los diversos niveles; se restauraron todas las carpinterías históricas exteriores e interiores, así como las rejerías y los pavimentos de baldosa hidráulica. Esta intervención, aparentemente rutinaria, de rehabilitación de un edificio común en un centro histórico ha tratado de demostrar que la estratificación de la arquitectura, la conservación de la materialidad, la valorización de la historia, no están reñidas con la posibilidad de un uso contemporáneo de los edificios patrimoniales (Fig. 18). 


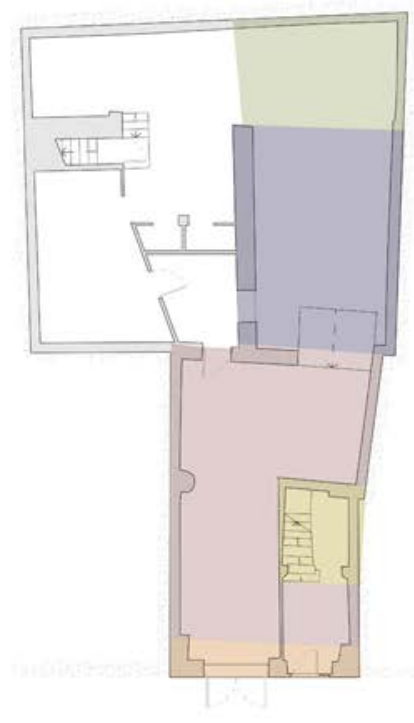

planta baja

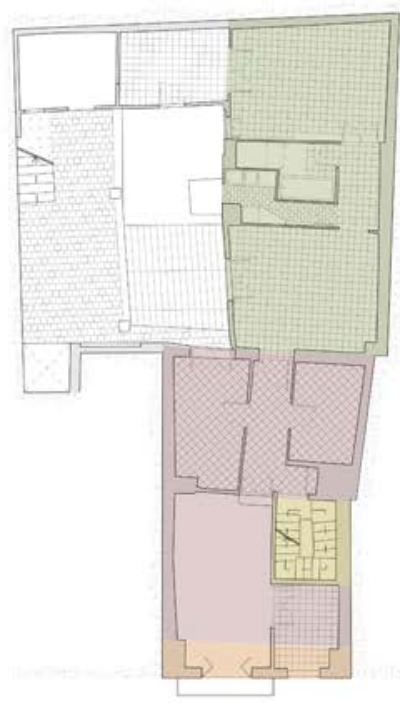

planta 2

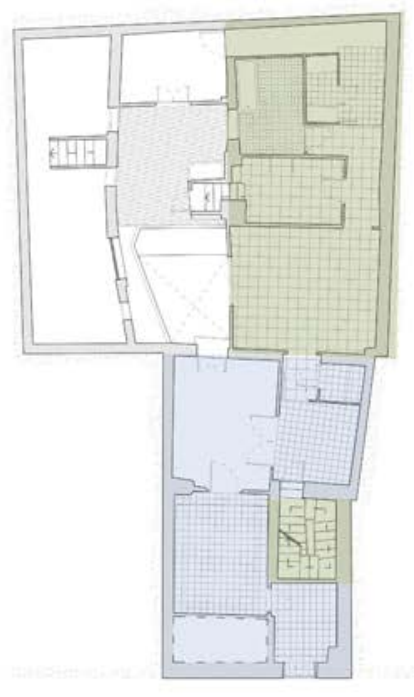

planta 1

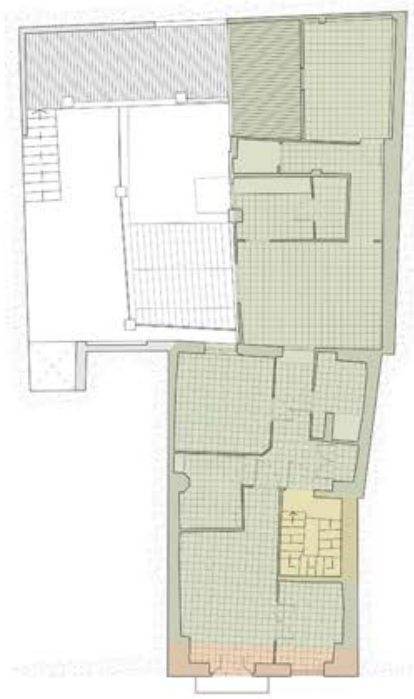

planta 3
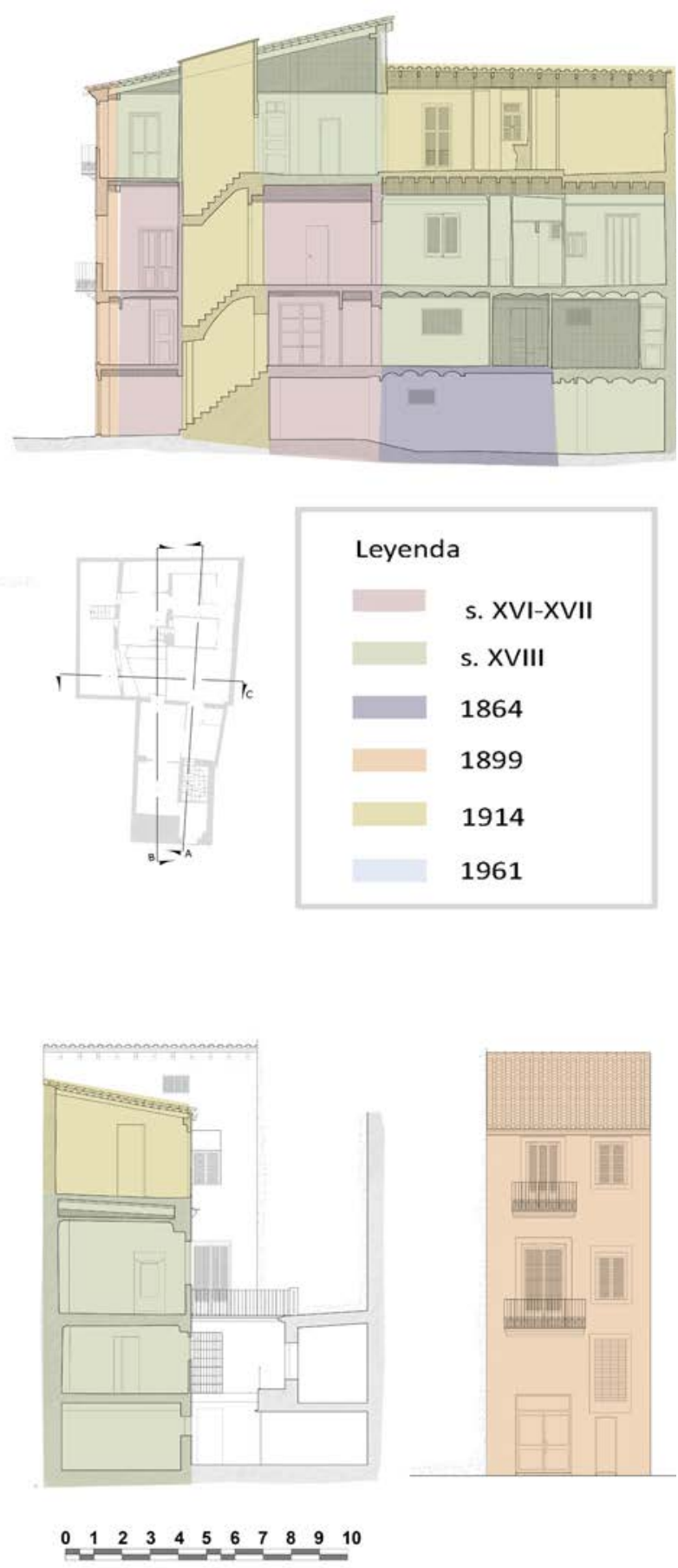

Figura 16. Hipótesis de las etapas de construcción y transformación del edificio de viviendas en la Calle Maldonado 33 (Valencia). Autores: Mileto y Vegas 

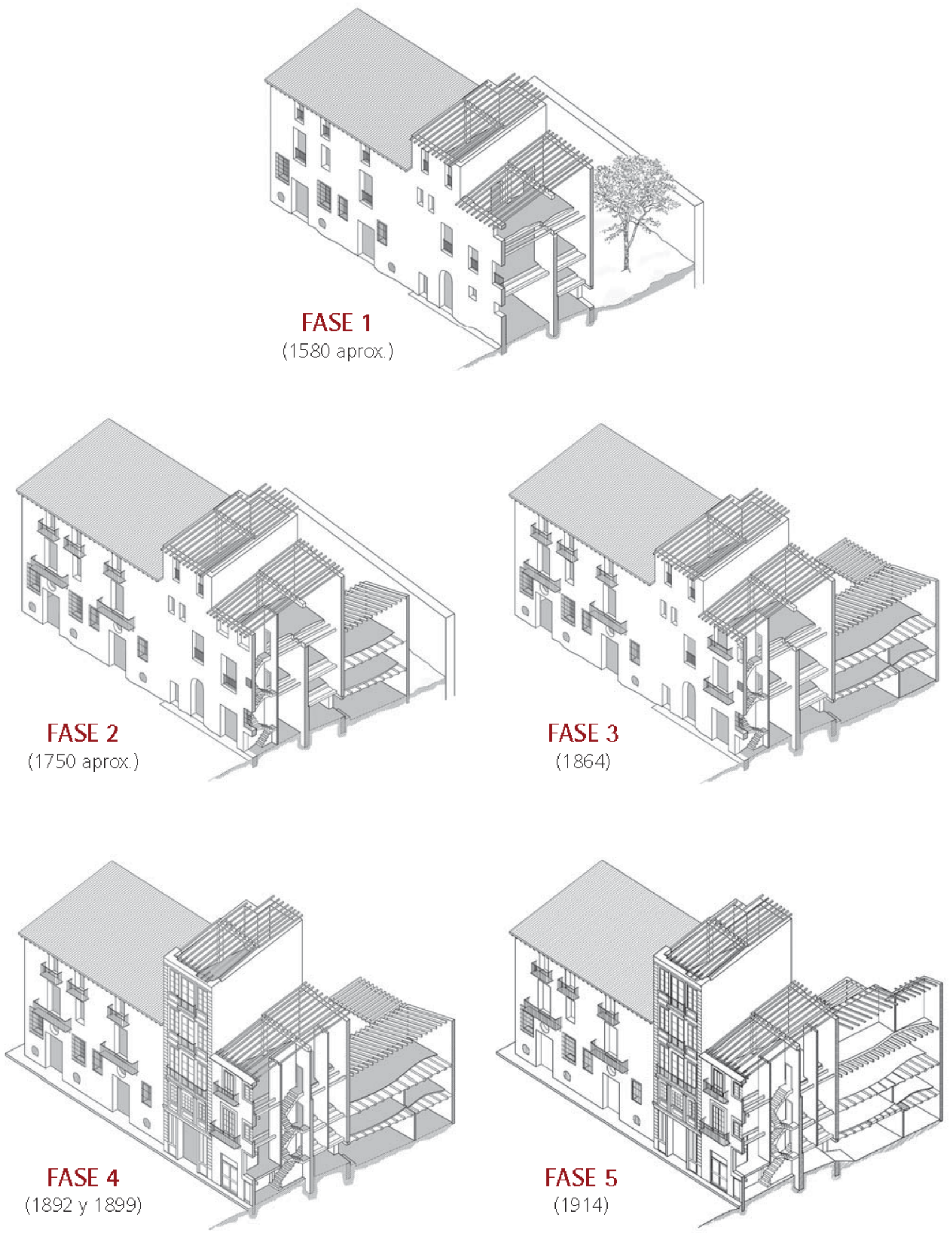

Figura 17. Reconstrucción de la hipótesis de las etapas de construcción y transformación del edificio de viviendas en la Calle Maldonado 33 (Valencia). Autores: Mileto y Vegas. 


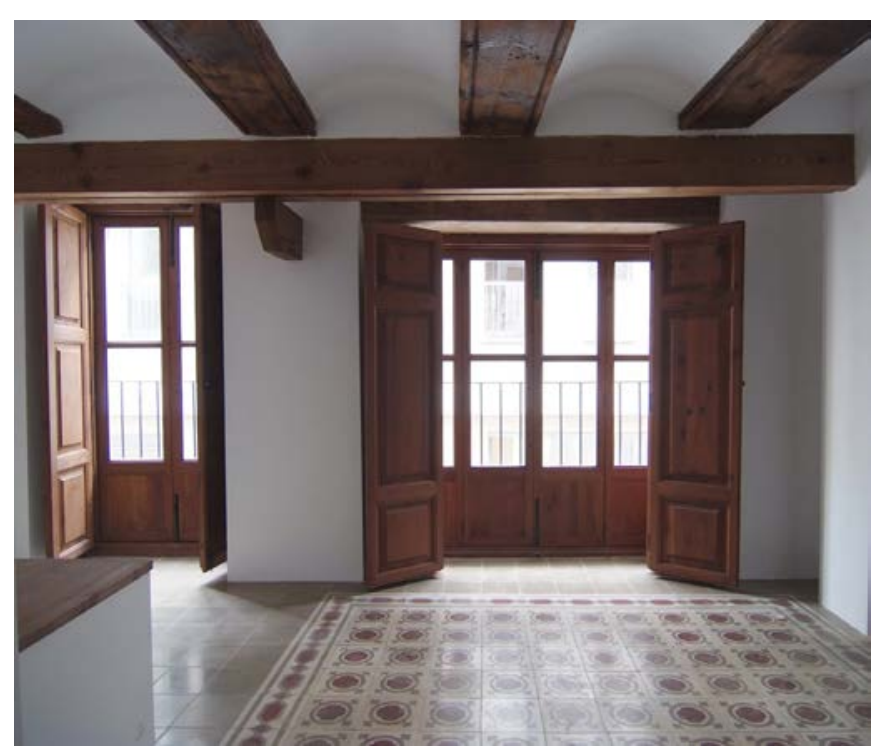

Figura 18. Interior de una de las viviendas del edificio de viviendas en la Calle Maldonado 33 (Valencia) tras la obra de rehabilitación. Fotografía Mileto y Vegas.

\subsection{El Palacio del Barón de Herbés}

El Palacio del Barón de Herbés se sitúa en la parte alta de la colina que domina la población de Herbés en la provincia de Castellón (Fig. 19). La villa fue conquistada por Blasco de Alagón en 1232 y cedida en señorío al caballero aragonés Juan Garcés de Juanes. Desde finales del siglo XIII hasta 1382 los Centelles fueron señores de Herbés y se tiene noticia de su residencia en el palacio (Mileto et al. 2012). Desde ese momento se sucedieron como señores de esta población y dueños del palacio los Cubells hasta finales del siglo XV, los Valls hasta finales del siglo XVII y los Ram de Viu que utilizaron el palacio desde principios del siglo XVIII hasta hace unos pocos años.

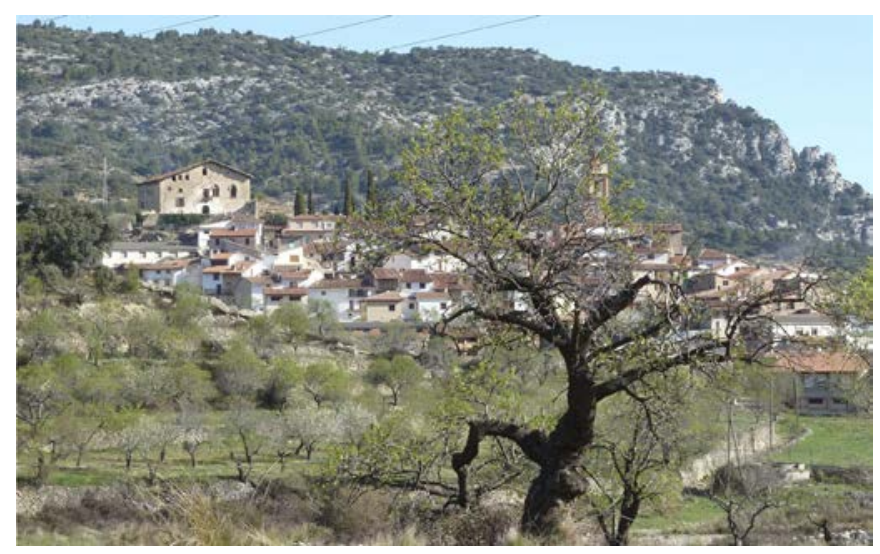

Figura 19. El Palacio del Barón de Herbés (Herbés, Castellón) en su contexto urbano y paisajístico. Fotografía Mileto y Vegas.
En el año 2011 se encargó la restauración de la cubierta a los arquitectos que escriben este texto. En esa circunstancia se aprovechó para desarrollar un primer estudio del palacio. Además del estudio detallado de la cubierta que era el objeto principal de la intervención, se realizó un estudio histórico y de los elementos arquitectónicos y decorativos, un levantamiento métricodescriptivo, un estudio estratigráfico, un estudio de los materiales y técnicas constructivas y un estudio de los problemas de conservación material y estructural (Fig. 20). El estudio estratigráfico se desarrolló con la aplicación de las nuevas tecnologías que permiten realizar una toma de datos in situ de gran detalle (Fig. 21) que luego se puede reelaborar en los planos de lectura e interpretación y en el diagrama de Harris.

Esta primera fase de estudio que, vista la complejidad del objeto, requeriría ulteriores fases de profundización, ha puesto en evidencia cómo el palacio, en la actualidad, es el fruto de continuas remodelaciones debidas a los diversos dueños que se sucedieron, con el objetivo de demostrar su poderío a través de la arquitectura. El palacio manifiesta su vocación de arquitecturaimagen a través de los diversos escudos presentes en los muros, ventanas, pavimentos, carpinterías. Se trató en varios casos de intervenciones orientadas a dignificar una arquitectura que era sencilla de partida a través por ejemplo- de la recolocación de ventanas de diversa época probablemente a mediados del siglo XVII. Estas ventanas, dispuestas en L en los lados norte y este, configuran el que tuvo que ser el salón principal y sobre todo confieren cierto empaque a los dos lados del palacio que se perciben desde el camino de entrada al mismo.

Una importante operación de remodelación fue la que se llevó a cabo a mediados del siglo XVI en las estancias del entresuelo. Se trata de cuatro estancias, probablemente remodeladas entre 1536 y 1559 cuando Bartomeu Valls fue señor de Herbés, con forjados de vigas de madera y revoltones de yeso vertido sobre molde con decoración renacentista, pavimentos de baldosas de cerámica con el escudo de los Valls y puertas de paso con molduras de yeso y carpinterías con diseños propios de la cultura renacentista ${ }^{23}$. Las ventanas exteriores se insertaron en rotura sobre las diversas fábricas que caracterizan este cuerpo del palacio. Estas estancias, con el tiempo, se fueron encalando con múltiples capas hasta las últimas coloreadas con azulete. Esta superposición

\footnotetext{
23 Véase: Vegas, F., Mileto, C. e Iborra, F. 2012: Elementos arquitectónicos y decorativos del Castillo de Herbés Castellón, documento inédito
} 

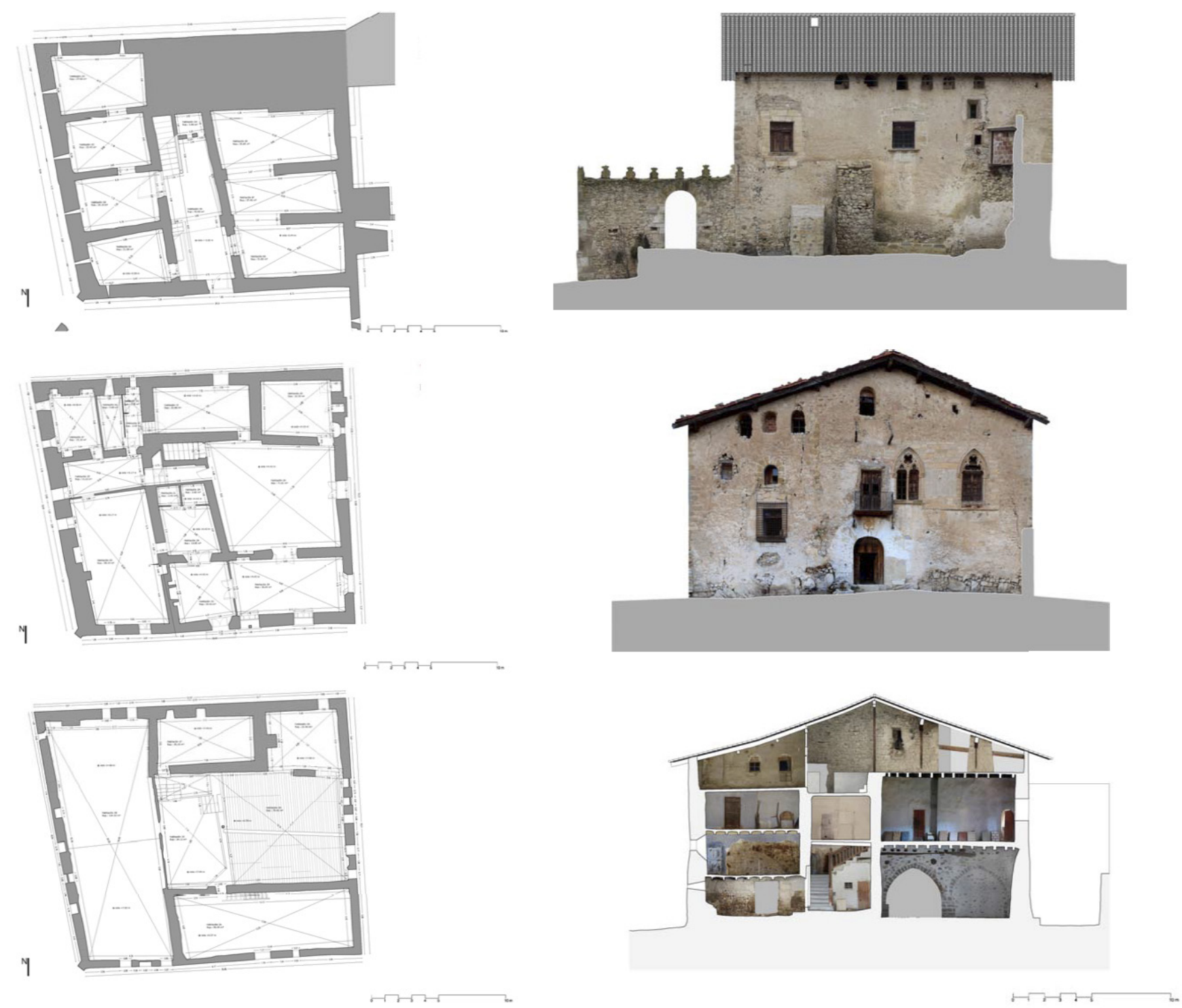

Figura 20. Levantamiento métrico del Palacio del Barón de Herbés (Herbés, Castellón) donde se puede apreciar la complejidad de crujías, nivelas y elementos que denuncian una historia de transformaciones del edificio. Autores Mileto y Vegas

de capas desdibujó los detalles decorativos de las molduras de forma que las estancias habían pasado completamente desapercibidas recientemente (Fig. 22). Las primeras actuaciones de limpieza de estas estancias, realizadas por unos restauradores cualificados, ha sacado a la luz un conjunto con elementos decorativos de yeso, policromías y rótulo de notable calidad y finura (Fig. 23).

Poco antes de la realización de este estudio, se habían realizado unas obras de "restauración" en algunas salas de la planta baja del palacio para acondicionar estas zonas para un posible uso público. Las estancias intervenidas en la planta baja del ala este del palacio se configuraban por amplios arcos fajones de sillería y muros de mampostería transversales respecto a la longitud de la sala. Los responsables de la intervención entendieron que la misma estructura debía de encontrarse también en el cuerpo oeste del palacio y picaron en varios tramos el revestimiento de las salas renacentistas (Fig. 24) que se encontraban en el entresuelo, encontrando evidentemente los arcos fajones cuyos arranques eran bien visibles en la planta baja del mismo cuerpo. Esta acción irresponsable y falta de fundamento dirigida a la búsqueda de los arcos medievales ha dañado para siempre las estancias renacentistas, mermando hasta los rótulos que hacían referencia al mecenas humanista que había sido responsable de la construcción de esta joya arquitectónica en un perdido valle de montaña. 
ธิธ

๑)

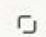

(10) 20

ロ

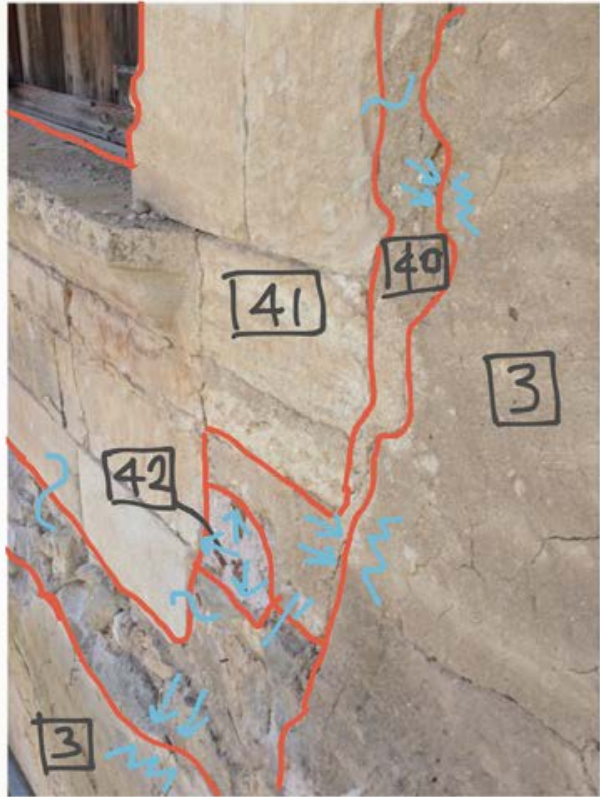

$\cdots$

Figura 21. Toma de datos estratigráfico realizada en situ con medios digitales para el estudio del Palacio del Barón de Herbés (Herbés, Castellón). Autores Mileto y Vegas.

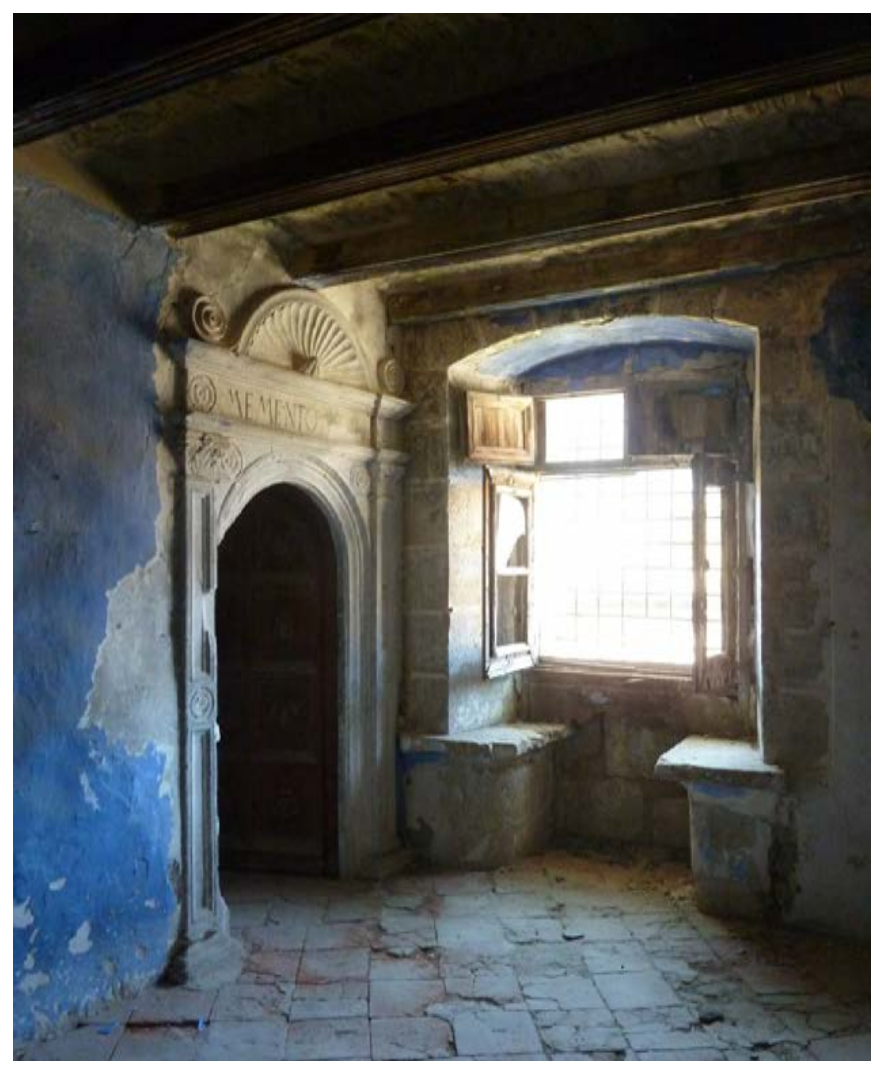

Figura 22. Primera de las cuatro salas renacentistas del Palacio del Barón de Herbés (Herbés, Castellón). Fotografía Mileto y Vegas.

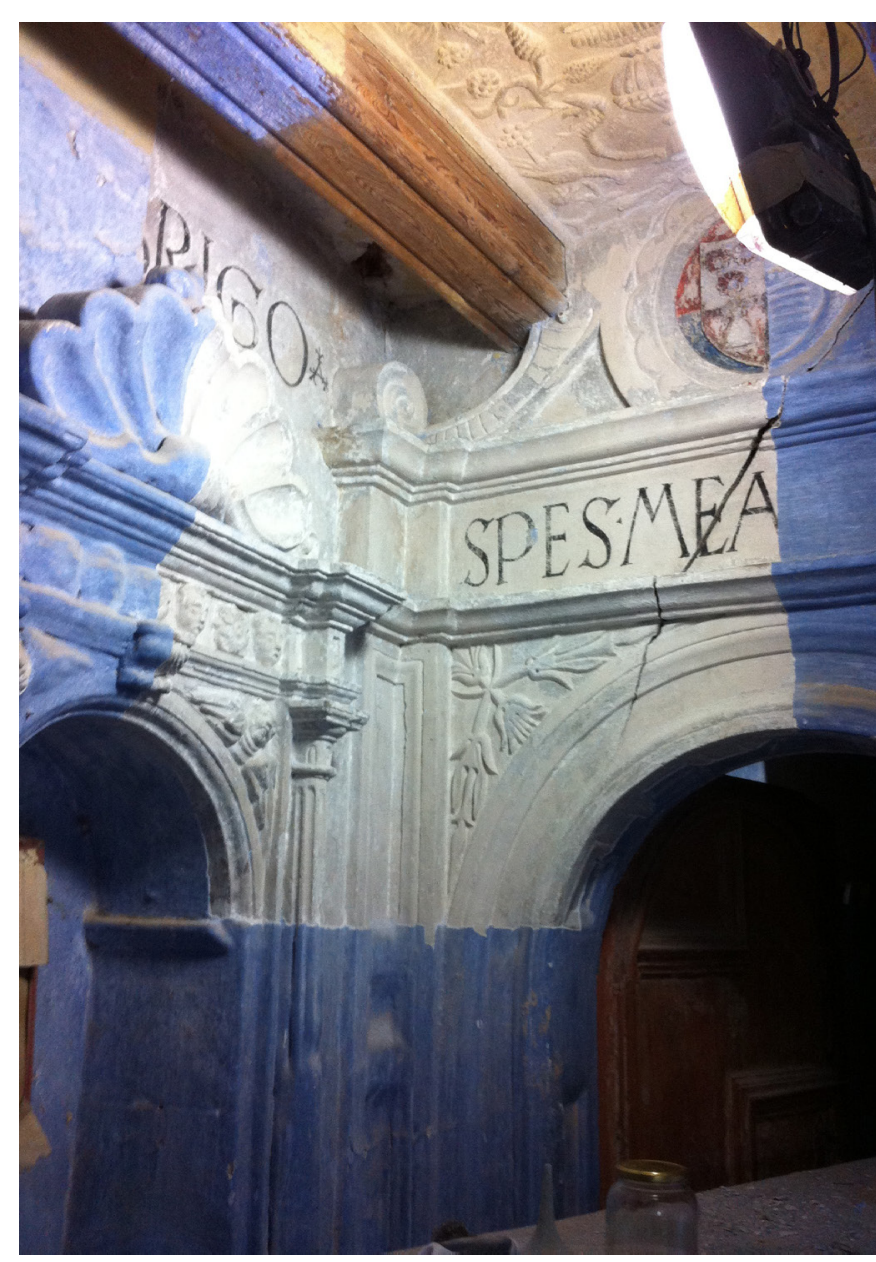

Figura 23. La prueba de limpieza de las decoraciones de yeso de la puerta de la cuarta sala renacentista del Palacio del Barón de Herbés (Herbés, Castellón) descubre la calidad y la finura de la talla y la policromía. Fotografía Mileto y Vegas.

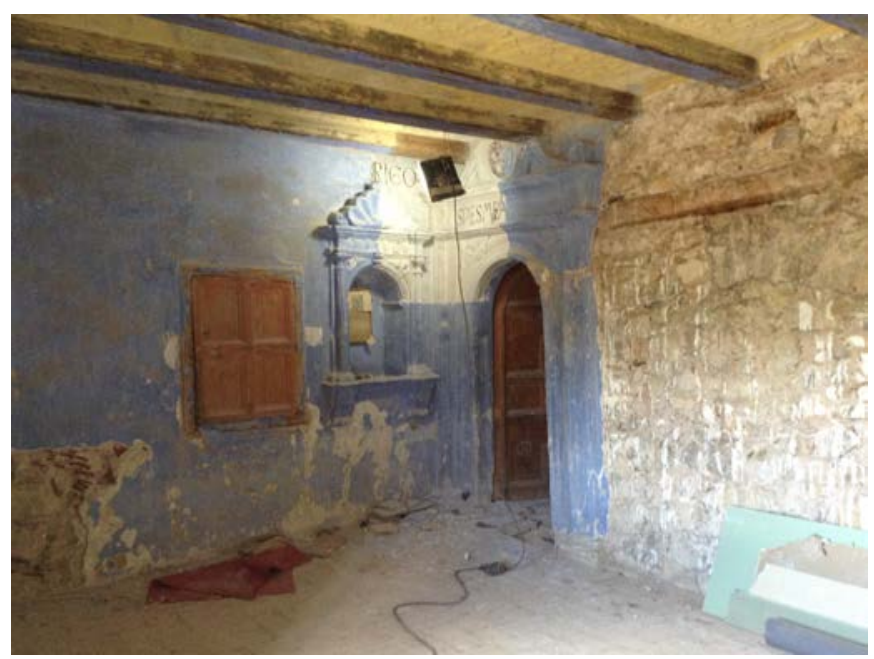

Figura 24. El daño provocado por el picado del revestimiento renacentista realizado en la cuarta sala renacentista del Palacio del Barón de Herbés (Herbés, Castellón) antes de su estudio y proyecto de restauración. Fotografía Mileto y Vegas. 


\section{REFLEXIONES PARA UN CRECIMIENTO COMÚN}

La colaboración interdisciplinar entre restauración arquitectónica y arqueología de la arquitectura, que se desarrolló a partir de los años ochenta, ha contribuido al avance de ambas disciplinas. La restauración arquitectónica ha desarrollado desde sus inicios la necesidad de la aplicación de una metodología como base del estudio del edificio que tiene que guiar el proyecto ${ }^{24}$. La arqueología de la arquitectura ha aportado diversos métodos (el análisis estratigráfico, la cronotipología, los métodos de datación, etc.) para la lectura y análisis de los datos materiales y para su datación e interpretación histórica que ha permitido fundamentar y organizar las observaciones que desde siempre el restaurador realizaba en relación con la transformación del edificio. La arqueología de la arquitectura ha aportado en este sentido métodos y objetividad a la restauración arquitectónica y ha contribuido sin duda a aumentar la mirada científica en el proyecto de restauración.

Por otro lado, el estudio atento de las diversas fases constructivas y de los mecanismos de estratificación ha afianzado en el arquitecto restaurador la conciencia de la necesidad de la conservación de todas las fases de la construcción que ya existía como principio de la disciplina en la Carta de Atenas de 1931 aunque siguen existiendo en la actualidad intervenciones que eliminan los "añadidos" bajo la presión de un juicio de valor. Sin embargo, de una forma cada vez más general, se entiende el patrimonio arquitectónico como la suma de todas las fases constructivas y su restauración está ligada a la conservación de esta transformación, más que solo de una etapa concreta y representativa en la historia. La propia restauración arquitectónica se entiende en la actualidad como una fase más de esta cadena de transformaciones. La mirada como percepción, en la actualidad, acepta la fragmentación, la discontinuidad y la complejidad por lo que la unidad arquitectónica, que ya no constituye hace tiempo un objetivo científico, tampoco se requiere a nivel perceptivo o estético.

De una forma totalmente paralela a la lectura de la estratificación, la intervención puede consistir en añadir o quitar materia respecto a lo preexistente. Esta

\footnotetext{
24 Desde sus inicios los padres de la restauración arquitectónica como Viollet-le-Duc o Boito han fundamentado sus intervenciones en el estudio atento de la materialidad del edificio. Ya en la Carta italiana de restauración de 1883 se abogaba por la necesidad de un estudio lo más completo posible del edificio para poder realizar la restauración
}

conciencia de la arquitectura en continua transformación se refleja en el proyecto de restauración que debe sumarse como una fase más de la historia, que no constituye el acto último y definitivo sino uno de los muchos periodos de la historia y que debe procurar permitir su lectura e interpretación en el futuro por lo que tiene que ser legible y posiblemente reversible, como se viene diciendo desde hace tiempo en las Cartas y documentos internacionales. Un ejemplo claro en este sentido es la restauración de la sala de la Barbería en la Alhambra, donde no se pretende transmitir una Alhambra solo islámica o renacentista, o romántica, o... Por el contrario, se quiere transmitir una Alhambra inclusiva: islámica y renacentista y fruto de la intervención del XIX y del $\mathrm{XX}, \mathrm{y} \ldots \mathrm{El}$ valor de este lugar es la suma de sus transformaciones, incluida la restauración que se realiza y las que se realizarán. Se plantea una historia compleja que tiene como resultado un lugar complejo que acoge y compatibiliza las diversas historias culturales, políticas, estéticas constructivas, sociales, de uso, de gusto, etc. En definitiva, una compleja y rica herencia del pasado valiosa para el futuro, una "topografía de las complejas constelaciones cotidianas de la sociedad" (Azkárate 2008).

La arqueología de la arquitectura ha favorecido claramente la fundamentación de estas reflexiones ya presentes desde los inicios de la disciplina que se apoyan en la concepción de la arquitectura histórica como documento materia ${ }^{25}$. Sin embargo, sobre todo la estratigrafía de la arquitectura ha favorecido la visualización de la implicación de las intervenciones en la legibilidad de la materia y la cuantificación de la pérdida de información ligada a la posible intervención de eliminación de los datos ${ }^{26}$.

La observación directa de las fábricas, de las relaciones estratigráficas, de la microestratigrafía relacionada con los procesos constructivos, han favorecido una relación de contacto directo con el edificio y la formación de una mirada específica, la mirada estratigráfica, que es capaz de interpretar las huellas y proyectar la intervención en función de las huellas que puede generar y la afección respecto a lo existente. Al mismo tiempo, el

\footnotetext{
25 Ruskin fue un gran defensor de la arquitectura como documento histórico y de memoria, postura que se heredó de forma programática y extrema en la teoría de la "pura conservación" defendida sobre todo por los italianos Bellini (2000) y Dezzi Bardeschi (1991). Pero el propio Boito defiende la arquitectura como documento de la historia, posición común a una serie de autores desde el inicio de la disciplina (Dezzi Bardeschi 2002).

26 Pensemos en este sentido al concepto de "autenticidad por relaciones" establecido por Francesco Doglioni. Cfr. Doglioni 2002.
} 
proyecto entendido de esta manera se relaciona directamente con la materia y no se limita a una idea abstracta. La intervención se proyecta en función de lo existente, de su conservación, puesta en valor y disfrute, aunque por supuesto incorpore constantemente las miradas culturales y sensibles, ligadas a hechos históricos y a sentimientos de identidad. Es este el caso de la intervención realizada para el jardín de las ruinas del convento de San Francisco en Vinaroz donde el proyecto, que surge claramente de la voluntad de expiar una culpa, de recuperar un espacio patrimonial para el uso público, de recuperar una identidad local, se acopla a los restos que emergen de la excavación que guían en todo momento la materialización del mismo.

Por otra parte, la arqueología de la arquitectura, gracias a las intervenciones de restauración y rehabilitación, tiene acceso cada vez más a edificios que estudiar ampliando así sus bases de datos y posibilidades de estudios cruzados. La realización de un proyecto de restauración es la ocasión para desarrollar unos estudios completos y amplios que involucren especialistas y disciplinas para que aporten sus contribuciones en el estudio del caso concreto, pero que a su vez puedan afinar sus propios métodos y procedimientos, ampliar sus datos y compararlos, crear nuevas relaciones y experimentar con técnicas y herramientas nuevas. Las intervenciones a menudo se desarrollan muy rápidamente creando unos límites en las posibilidades de desarrollo de los estudios y sus tiempos de maduración, pero por otra parte crean nuevas posibilidades y ocasiones de colaboración. Estas ocasiones se generan en el patrimonio monumental y con grandes presupuestos, pero también se crean en el día a día y en edificios más modestos. En este sentido, es interesante el caso del edificio de la calle Maldonado donde en una actuación de rehabilitación de un edificio de viviendas no catalogado la aportación de la arqueología de la arquitectura ha permitido entender el edificio en sus transformaciones y ponerlo en valor justamente como fruto de su estratificación. El estudio de este pequeño edificio se enlazó con otros estudios, catalogaciones, cronologías, etc. sobre edificios similares que permitieron avanzar en el conocimiento de la edificación residencial histórica de la ciudad de Valencia (Mileto y Vegas 2015). Acceder al edificio y a la información que custodia en sus entrañas durante una obra de restauración aporta una cantidad y calidad de información que de otra manera no podría recogerse y que puede constituir el pivote central para el avance del conocimiento de un determinado tipo de patrimonio o de aspectos del mismo y al crecimiento de la mirada cultural de quien realiza el proyecto, pero también de una comunidad.

La restauración arquitectónica y el estudio constructivo y estructural de la arquitectura también han favorecido la interpretación arqueológica donde el conocimiento de los materiales y los procedimientos de la construcción ayudan a la explicación de la transformación del propio edificio. En este sentido, la interpretación correcta de las técnicas constructivas con sus procedimientos, de los mecanismos de degradación y comportamiento estructural del edificio permiten entender e interpretar correctamente las huellas materiales y las transformaciones. Aunque el foco de atención de la arqueología sea el conjunto de los procesos sociales y culturales que generan las transformaciones, por otro lado, en el caso del estudio de la arquitectura, es fundamental tener en cuenta los mecanismos de la propia arquitectura como la construcción, la concepción estructural y espacial, el uso, las lesiones, los mecanismos de degradación material y estructural, etc. La técnica constructiva como fruto de un saber hacer de una determinada cultura ha sido un elemento de gran importancia del estudio arqueológico de la arquitectura desde sus inicios, aunque paralelamente se han explorado otros caminos como los estudios de la arqueología de la arquitectura relacionados con los mecanismos de degradación material y lesiones estructurales (Cagnoni 1996; Doglioni 1997; Franceschi y Lazzari 2001; Cámara 2010). Por ello, la restauración arquitectónica, como disciplina que se ocupa de estos aspectos, ha aportado sin duda nuevos horizontes y perspectivas a la arqueología de la arquitectura.

La colaboración entre arqueología de la arquitectura y restauración arquitectónica y, sobre todo, con la concepción de la restauración que valora la materialidad como documento y testigo de cultura material, permite una visión de una "arqueología conservativa". La necesidad de conocer no puede nunca prevalecer respecto a la conservación de la materialidad. Por tanto, la arqueología de la arquitectura no puede ser una disciplina de excavación, procedimiento que conllevaría la destrucción progresiva del propio edificio, objeto de estudio y conservación. También es necesaria la protección de las superficies de acabado y de los revestimientos que, aunque impidan la lectura directa de la fábrica, constituyen un elemento patrimonial a menudo de gran valor porque transmite los datos de una cultura de la producción material y constructiva, de su configuración arquitectónica 
y de los usos y modos de ocupación de los espacios. Aunque estos conceptos deberían estar plenamente asumidos por el sector de la restauración arquitectónica, a menudo se encuentran intervenciones que por diversas razones siguen perpetuando la práctica de la eliminación de los revestimientos bien por "sanear" la fábrica (expresión ampliamente utilizada en los proyectos de intervención) bien por "ver" la fábrica detrás del revestimiento. Un buen ejemplo de estas intervenciones es el estudio realizado en el Palacio del Barón de Herbés, donde detrás de la búsqueda de una información arquitectónica y de una configuración concreta se ha dañado irreparablemente un conjunto de estancias interiores de gran valor arquitectónico y patrimonial.

Por último, arqueología de la arquitectura y restauración arquitectónica están en los últimos años recorriendo un mismo camino hacia la ampliación del concepto de patrimonio que se está desarrollando en la cultura contemporánea. La arquitectura es una disciplina que amplía sus horizontes paralelamente a como se ha ido ampliando el concepto de patrimonio arquitectónico (monumental, vernáculo, paisajístico, cultural, materia e inmaterial, etc.). Restauración arquitectónica y arqueología se están enfrentando a un ámbito de trabajo cada vez más amplio donde lo material y lo inmaterial son cada vez más inseparables, donde caen las barreras temporales, donde los confines físicos del objeto de estudio se amplían hasta la escala paisajística y territorial y donde el trabajo de estudio, análisis, interpretación, proyecto, intervención se imbrican con la valorización, la promoción cultural, la gestión patrimonial, la participación social, la difusión y la comunicación. En esta perspectiva, los estímulos mutuos contribuyen al crecimiento y al afianzamiento, a la apertura de nuevas perspectivas y horizontes, al estímulo de nuevos caminos y posibilidades de recorrido.

\section{BIBLIOGRAFÍA}

AA. VV. 2002: Arqueología de la Arquitectura, 1, Vitoria-Gasteiz. https://doi. org/10.3989/arq arqt.2002.i1

AA. VV. 2003a: Arqueología de la Arquitectura, 2, Vitoria-Gasteiz. https:// doi.org/10.3989/arqarqt.2003.i2

AA. VV. 2003b: Repertorio de Textos Internacionales del Patrimonio Cultural. IAPH, Sevilla.

Alagna, A. 2008: Stratigrafia per il restauro architettonico. Aracne, Roma.

Almagro, A. 2008a: “El Salón Norte del Palacio al-Badi’ de Marrakech: Estudio arqueológico e hipótesis sobre su forma original", Arqueología de la Arquitectura, 10. https://doi.org/10.3989/arq.arqt.2014.003

Almagro, A. 2008b: "La puerta califal del castillo de Gormaz", Arqueología de la Arquitectura, 5, pp. 55-77. https://doi.org/10.3989/arq.arqt.2008.89
Arnheim, R. 1954: Art and visual perception - A psychology of the creative eye - The new version, The University of California Press, Berkeley, California [Trad. esp.: Arte y percepción visual. Psicología del ojo creador. Alianza, Madrid, 1979].

Azkárate, A. 2008: "La Arqueología de la Arquitectura en el siglo XXI", Arqueología de la Arquitectura, 5, pp. 11-13. https://doi.org/10.3989/arq. arqt.2008.86

Azkárate, A. 2013: "La construcción y lo construido. La Arqueología de la Arquitectura", en J. A. Quirós Castillo (ed.), La materialidad de la historia. La arqueología en los inicios del siglo XXI, pp. 271-298. Akal, Madrid.

Azkárate, A., Cámara, L., Lasagabaster, J. I. y Latorre, P. 2001: Catedral de Santa María de Vitoria-Gasteiz. Plan Director de Restauración. Diputación Foral de Alava, Vitoria-Gasteiz.

Azkárate, A. y Solaun, J. L. 2013: Arqueología e historia de una ciudad. Los orígenes de Vitoria-Gasteiz. Universidad del País Vasco, Vitoria-Gasteiz.

Baila Pallarés, M. A. 2012: Los conventos de Vinarós. Fundaciones, conflictos y frustraciones. Ed. Associaciò Cultural Amics de Vinaròs, Vinaroz.

Baldini, U. 1978: Teoria del restauro nell'unità di metodología. Nardini, Florencia

Bellini, A. 2000: "De la restauración a la conservación; de la estética a la ética", Loggia, 9, pp. 10-15. https://doi.org/10.4995/loggia.2000.5245

Beltramo, S. 2009: Stratigrafia dell'architettura e ricerca storica. Carocci, Roma.

Benjamin, Walter 1994: "Eduard Fuchs, il collezionista e lo storico", ANAГKH, 8, p. 15.

Blanco, R. 2017: "Arquitectura y paisaje. Aproximaciones desde la arqueología”, Arqueología de la Arquitectura, 14, pp. 155-162. https://doi. org/10.3989/arq.arqt.2017.007

Boato, A. 2008: L'archeologia in architettura. Marsilio, Venecia.

Brandi, C. 1963: Teoría del restauro. Einaudi, Turín.

Brogiolo, G. P. 1993: "Appunti su analisi stratigrafica e restauro", en M. Uboldi (coord.), Carta geologica della Lombardia. III, Como, la cittá murata e la convalle, pp. 103-108. Panini, Modena.

Bucaille, R. y Pesez, J.-M. 1978: "Cultura Materiale", en Enciclopedia Einaudi. Einaudi. Torino, vol. IV, ad vocem

Caballero Zoreda, L. y Cámara Muñoz, L. 1995: “Un caso de lectura de paramentos y argumentación científica. S. Pedro el Viejo de Arlanza, Burgos-España”, Informes de la Construcción, 46 (435), pp. 79-89. https:// doi.org/10.3989/ic.1995.v46.i435.1100

Caballero Zoreda, L. 1997: “Análisis arqueológico de construcciones históricas en España. Estado de la cuestión”, Archeologia dell'Architettura, 2, pp. 147-158.

Cagnoni, G. 1996: "Dal cantiere al metodo: stratigrafia e dissesto", Actas del I Seminario di Specializzazione in Archeologia dell'architettura: dalla conoscenza al restauro. Asociación Ricerche e Fortificazioni Altomedioevali, Padua, s/p.

Cámara, L. 2010: "Estratigrafía, evolución estructural y restauración. El caso de la iglesia de Santa Eulalia en Marqínez Álava", Arqueología de la Arquitectura, 7, pp. 225-260. https://doi.org/10.3989/arqarqt.2010.10006

Canivell, J. y Graciani, A. 2015: "Caracterización constructiva de las fábricas de tapia en las fortificaciones almohades del antiguo Reino de Sevilla”, Arqueología de la Arquitectura, 12, e025. https://doi.org/10.3989/arq. arqt.2015.003

Criado Boado, F. 2012: Arqueológicas. La razón perdida. Bellaterra, Barcelona.

Cristini, V. 2008: "Estudio de las fábricas de ladrillo en Valencia: análisis mensiocronológico y técnicas de acabado s. XVII-XVIII", Arqueología de la Arquitectura, 5, pp. 243-252. https://doi.org/10.3989/arq.arqt.2008.98

Dezzi Bardeschi, M. 1991: Restauro: punto y a capo. Frammenti per una (impossibile) teoria. Franco Angeli, Milán.

Dezzi Bardeschi, M. 2002: "<Conservare, non restaurare> (Hugo, Ruskin, Boito, Dehio e dintorni). Breve storia e suggerimenti per la conservazione in questo nuovo millenio", $A N A \Gamma K H, 35-36$, pp. 2-21.

Doglioni, F. 1990: "La superfici: considerazioni sui mutamenti prodotti dal restauro", en Superfici dell'Archietettura: la finiture, actas del Convegno di Studi di Bressanone, pp. 715-718 Progetto, Padua. 
Doglioni, F. 1993: "Restauración de la Villa Saraceno. Vicenza 1990", en AA.VV., Estrategias de intervención, pp. 168-186. COACV, Valencia. Doglioni, F. 1997: Stratigrafia e restauro. Lint, Trieste.

Doglioni, F. 2002: "Ruolo e salvaguardia delle evidenze stratigrafiche nel progetto e nel cantiere di restauro", Arqueología de la Arquitectura, 1, pp. 113-130. https://doi.org/10.3989/arq.arqt.2002.10

Doglioni, F. 2008: Nel restauro. Progetti per le architetture del passato. Marsilio, Venecia.

Dorfles, G. 1958: Le oscillazioni del gusto. Lerici, Milán.

España. Ley 16/1985, de 25 de junio, del Patrimonio Histórico Español, Boletín Oficial del Estado 155, 1985.

Franceschi, S. y Lazzari, A. 2001: "Significati e configurazioni del degrado nel progetto di restauro sulle superfici esterne del castello di Valbona PD", Arqueologia dell'Architettura, n. V, pp. 243-253.

Francovich, R. 1982: "Restauro architettonico ed archeologia stratigrafica", en G. Pietramellara y L. Marino (coords.), Contributi sul "Restauro archeologico", pp. 59-68. Alinea, Florencia.

Francovich, R. 1985: "Archeologia e restauro: da contiguitá a unitarietá", Restauro e Cittá, 2, pp. 14-20.

Francovich, R. 1988: "Archeologia e restauro dei monumenti. Nota introduttiva”, en R. Francovich y R. Parenti, Archeologia e restauro dei monumenti, pp. 13-27. All'Insegna del Giglio, Florencia.

González Moreno-Navarro, A. 2002: “Los estudios científicos-técnicos en el proceso de restauración monumental. Estado de la cuestión", en Quaderns Cientifics i tècnics de restauració monumental. I Bienal de la restauració monumental, pp. 131-140. Diputación de Barcelona, Barcelona.

Graciani, A. y Tabales, M. A. 2008: "El tapial en el área sevillana. Avance cronotipológico estructural", Arqueología de la Arquitectura, 5, pp. 135-158.

Jiménez, A. y Pinto, F. 2003: Levantamiento y análisis de edificios. Tradición y futuro, Sevilla.

Koffka, K. 1935: Principles of Gestalt Psychology [Trad. it.: Principi di psicologia della forma, Boringhieri, Turín, 1970].

Köhler, W. 1947: Gestalt Psychology, Liveright, Nueva York. [Trad. it.: La psicologia della Gestalt, Feltrinelli, Milán, 1961].

Latorre, P. 1988: "El sitio histórico de Melque pro. Toledo. La intervención integrada con una finalidad didactica", en R. Francovich y R. Parenti, Archeologia e restauro dei monumenti, pp. 157-194. All'Insegna del Giglio, Florencia.

Latorre, P. y Caballero L. 1995: "Análisis arqueológico de los paramentos del faro romano llamado Torre de Hércules La Coruña, España”, en AA. VV., Leer el documento construido, Informes de la construcción, $\mathrm{n}^{\mathrm{o}} 435$, pp. 47-50. Instituto Eduardo Torroja, Madrid.

López Mullor, A. 1998: “Arqueología del patrimonio edificado. Una definición y dos ejemplos", en Actas del Congreso internacional de restauración “Restaurar la Memoria”, pp. 139-165. Diputación de Valladolid, Valladolid.

López Mullor, A. 2010: "La construcción de un método de intervención en el patrimonio arqueológico edificado", en C. Martín y E. Vega, Arqueología aplicada al estudio e interpretación de edificios históricos: últimas tendencias metodológicas, pp. 65-101. Ministerio de Cultura, Madrid.

López Osorio, J. M. y Torres Carbonell, J. M. 2008: "El análisis estratigráfico del baño árabe de Churriana de la Vega Granada: la síntesis del conocimiento como base del proyecto de restauración", Arqueología de la Arquitectura, 5, pp. 187-205.

Martín, C. y Vega, E. 2010: Arqueología aplicada al estudio e interpretación de edificios históricos: últimas tendencias metodológicas. Ministerio de Cultura, Madrid.
Martínez Justicia, M. J. y Sánchez-Mesa, L. 2008: La restauración de los bienes culturales en los textos normativos. Comares Ed., Granada.

Mileto, C. 2006: "La conservación de la arquitectura: materia y mensajes sensibles", Loggia - Arquitectura y restauración, 19, pp. 20-33.

Mileto, C. y Vegas F. 2004: "El análisis estratigráfico constructivo y el proyecto de restauración arquitectónica", en Arqueología de la Arquitectura, 3 , pp. 155-162.

Mileto, C. y Vegas F. 2014: "Edificio Recaredo", CyTET. Ciudad y Territorio. Estudios territoriales, XLVI, 181, pp. 533-538.

Mileto, C. y Vegas F. 2015: Centro histórico de Valencia. Ocho siglos de arquitectura residencial. General de Ediciones de Arquitectura, Valencia.

Mileto, C. y Vegas F. 2016: "Il Giardino della memoria", Paesaggio Urbano, 3, pp. 26-33 [“El jardín de la memoria”, CyTET. Ciudad y Territorio. Estudios territoriales, 190, pp. 717-724].

Mileto, C. y Vegas F. 2017: "Protección del Patrimonio en España: entre gobierno central y autonomías", en C. Manfredi, Le politiche di tutela del patrimonio construido. Modelli a confronto in Europa, pp. 65-79. Milán, Mimesis.

Mileto, C., Vegas, F., Cristini, V. y Diodato, M. 2011: "Learning based upon projects of architectural conservation: from university to real life", en AA.VV., INTED2011 Proceedings, s/p. IATED.

Mileto, C., Vegas, F. y Noguera, J. F. 2008: "Preservation as a new compulsory subject in the curriculum of architecture. The experience in the school of Valencia", en AA.VV., INTED 2008 Proceedings, s/p. IATED.

Noguera, J. F. 2002: "La conservación activa del patrimonio arquitectónico", en Loggia - Arquitectura y Restauración, 13, pp. 10-31.

Philippot P. 1972: Historic Preservation: Philosophy, Criteria, Guidelines, en Preservation and Conservation: Principles and Practice. Philadelphia.

Quirós, J. A. 2002: "Arqueología de la Arquitectura en España", Arqueología de la Arquitectura, 1, pág. 27-38.

Rella, F. 1990: Bellezza e veritá. Feltrinelli, Milán.

Squassina, A. 2008: "La casa dell'abate a San Giovanni in Persiceto: indagini conoscitive e questioni operative per la conservazione di un edificiofossile", Arqueología de la Arquitectura, 5, pp. 207-222.

Tabales, M. A. 1997: “Análisis arqueológico de paramentos. Aplicación en el patrimonio edificado sevillano", SPAL. Revista de prehistoria y arqueología, 6, pp. 263-295.

Tabales, M. A. 2002a: “Arqueología y rehabilitación en Sevilla. Desarrollo metodológico y práctico”, Arqueología de la Arquitectura, 1, pp. 193-206.

Tabales, M. A. 2002b: Sistema de análisis arqueológico de edificios históricos, Universidad de Sevilla

Trías, E. 1991: Lógica del límite. Destino, Barcelona.

Utrero, M. A. 2010: “Archeology. Archeologia. Arqueología. Hacia el análisis de la Arquitectura", en C. Martín y E. Vega, Arqueología aplicada al estudio e interpretación de edificios históricos: últimas tendencias metodológicas, pp. 11-23. Ministerio de Cultura, Madrid.

Vargas Lorenzo, C. 2013: "Reflexiones sobre cronotipologías en Arqueología de la Arquitectura", Arqueología de la Arquitectura, 10: e001. doi: http:// dx.doi.org/10.3989/arq.arqt.2013.001

Vegas, F. y Mileto, C. 2010: "Intervención y propuesta de uso del espacio junto a la entrada del Mexuar", Cuadernos de la Alhambra, 45, pp. 91121.

Vegas, F. y Mileto, C. 2016: "Dalla Tabula Rasa al Giardino archeologico. Il Giardino archeologico di Vinaroz", Arkos, 15-16, pp. 61-77.

Zambrano, M. 1987: Hacia un saber del alma. Alianza, Madrid. 